\title{
MUNICIPALIZACIÓN DEL GOBIERNO INDÍGENA E INDIANIZACIÓN DEL GOBIERNO MUNICIPAL EN AMÉRICA LATINA ${ }^{1}$
}

\author{
Araceli Burguete Cal y Mayor \\ araceli_burguete@yahoo.com.mx \\ CIESAS-Sureste \\ Chiapas, México
}

\section{RESUMEN}

Esta colaboración se aproxima al proceso de municipalización del gobierno local indígena y a la otra cara del mismo proceso: la indianización del gobierno municipal, en América Latina. En las últimas tres décadas el municipio se ha reformado, en un marco más amplio de reforma del Estado, para ajustarse al nuevo contexto neoliberal A este proceso se le ha llamado «neomunicipalismo». Para diversos pueblos indígenas, el «neomunicipalismo» se percibe como un riesgo, pero también como una oportunidad. En el pasado reciente, el gobierno indígena fue visto desde el poder del Estado como «remanentes» en vías de disolución. Hoy día, el Estado multicultural acepta como válidas esas instituciones, siempre y cuando se inscriban en la lógica de la organización del Estado. Requisito que diversas organizaciones perciben como un riesgo, aunque otras lo ven como una oportunidad para avanzar en el proceso de empoderamiento indígena. El dilema entre resistencia y no aceptación de la institucionalidad del Estado, y el acceso a las mismas, en un horizonte de apropiación, es una vieja historia en la relación pueblos indígenas y municipio. Cuando hay aceptación — siempre limitada - se producen procesos de «municipalización» del gobierno indígena. En esta colaboración sistematizo tres momentos de municipalización del gobierno indígena en América Latina: cabildo indígena colonial, ayuntamiento gaditano, neomunicipalismo.

Palabras clave: gobierno indígena, municipalización, indianización, neomunicipalismo. 


\section{SUMMARY}

This collaboration is approaching the municipalization process of local government and indigenous on the other side of the same process: the indianization of the municipal government, in Latin America In the last three decades, in a broad framework for reform of the State, the municipality has been refurbished, in a broader framework for reform of the State to comply with the new neoliberal context. The «neomunicipalismo», is a risk and an opportunity for these peoples. In the recent past, the institutions the indigenous government, was seen as «residual» in the process of dissolution. Today, the multicultural State accepts as valid those institutions, always and when entered in the logic of the organization of the State. Requirement that various organizations perceive as a risk; but other see it as an opportunity to make progress in the process of empowering indigenous. The dilemma between resistance and non-acceptance of the institutional framework of the State, and access to the same, in a horizon of appropriation, is an old story in the relationship indigenous peoples and municipality. In this collaboration systematized three stages of municipalization of the indigenous governance: the cabildo indigenous colonial; the cádiz city hall andthe neomunicipalismo.

Key words: indigenous governance, municipalization, indianization, neomunicipalismo. 
El gobierno indígena en América Latina se ha configurado, en un proceso de larga duración, en un diálogo tenso con las trasformaciones de su entorno. El gobierno indígena encuentra su explicación en la persistencia de un hilo continuo de un sistema de autoridades que es percibido como propio Esas instituciones, sin embargo, no se construyen en la autarquía o aislamiento; por el contrario, se configuran en el diálogo constante con la institucionalidad estatal. Distingue al gobierno indígena su capacidad para reelaborar las instituciones estatales, que siendo «ajenas» son convertidas en propias mediante complejos procesos de apropiación — «indianización»—, que son resultado de la voluntad de estos pueblos para hacer persistir la diferencia. Su persistencia - y en lo general de los pueblos indígenas en sí mismos y de sus propias instituciones - debe explicarse en su capacidad para adecuarse a las realidades nacionales y el contexto más amplio. En las páginas siguientes voy a aproximarme a esas trasformaciones, intentando mostrar la adecuación y reconfiguración continua de los gobiernos indígenas, mediante procesos de municipalización, en distintos momentos históricos.

Los pueblos indígenas en América Latina siguen practicando formas de autogobierno regidas por normas que perciben como propias. El gobierno indígena en América Latina, y aun dentro de cada país, no tiene un diseño único, sino que es tan diverso como distinta se presenta la realidad en la que cada uno de ellos se constituye: en un contexto de múltiples determinaciones, relaciones y articulaciones. Pese a las diferencias, comparten rasgos que vistos en conjunto permiten su caracterización como tales. Con excepción de algunos pueblos de las tierras bajas — de la amazonía, por ejemplo, en donde «el contacto» cultural ha sido escaso-, en el resto el gobierno indígena se ha configurado, regularmente, en diálogo con la institución municipal gubernamental, en distintos momentos históricos, durante cinco siglos. El gobierno indígena de la región comparte la característica de haber hecho de la institución municipal - ya sea como república de indios, cabildo o ayuntamiento - algo apropiado, en una interrelación tensa entre «municipalización del gobierno indígena»—como política de Estado, para la asimilación-, y de «indianización del gobierno municipal», como estrategia de resistencia; de lo que resulta que en los contextos indígenas la institución municipal se haya constituido en un marco de interlegalidad (Burguete 2008a). 
El trasfondo teórico del argumento que aquí desarrollo se inspira, desde la Antropología jurídica, en un enfoque de interlegalidad. Toma distancia de la perspectiva del pluralismo jurídico, que observa dos polos o sistemas paralelos, uno como tradición y el otro como modernidad, como costumbre y ley, escritura y oralidad, como sistemas que coexisten entre sí, de un Estado que tolera las costumbres indígenas y que explica la permanencia de las instituciones indígenas como un mundo autárquico y ensimismado. La perspectiva de interlegalidad, desarrollada por Boaventura de Sousa Santos (2003), por el contrario presume diálogo constante y mutua constitución. La noción de interlegalidad remite a la porosidad del mundo jurídico, lo que da lugar a un derecho constituido por múltiples redes de juridicidad.

Esa perspectiva teórica y metodológica aquí asumida considera los sistemas normativos y las instituciones indígenas como entidades dinámicas y flexibles insertas en procesos históricos de poder y de cambio socio-jurídico (Sierra 2005). Así tanto el gobierno indígena como el municipio indígena, en el sentido de instituciones, se han gestado en una relación continua con el orden jurídico estatal con el que interactúan. En esta configuración, el Estado también se modifica al realizar cambios en su organización y perspectiva cultural - como hoy es claramente visible mediante las reformas multiculturales-; de lo que resulta su mutua constitución. ${ }^{2}$ Es importante mencionar que los campos jurídicos que incluyen el municipio y el gobierno indígena son más amplios de lo que se aborda. Los hay que toman en cuenta el contacto del reconocimiento jurídico de las comunidades campesinas e indígenas, la jurisdicción étnica, la territorialidad y tenencia de la tierra, el sistema de autoridades — que va más allá de lo municipal—, los sistemas normativos, la ciudadanía y la pertenencia étnica. Temas subyacentes a los debates que cruzan esta colaboración, pero que no desarrollo por razones de espacio.

En las últimas tres décadas el gobierno indígena se ha visto impactado por los cambios que han sufrido los Estados nacionales en América Latina, como resultado de reformas, globalización y de expansión del capitalismo neoliberal. En este contexto, los gobiernos locales indígenas en América Latina también han cambiado. De los más importantes cambios se presenta una institución municipal modificada resultado de las políticas de descentralización y de democratización en la región. Esta «neomunicipalización»—entendida como adecuación del municipio a la reforma del Estado neoliberal— ha sido una estrategia 
desplegada desde el Estado reformado para ampliar su presencia, sus competencias, su capacidad de regulación hacia las regiones indígenas; al mismo tiempo que se reorganiza para adecuarse a los cambios del entorno global y de las presiones del mercado.

Al curso de los años ochenta y noventa, la mayoría de los nuevos gobiernos democráticos en América Latina sufrió un deterioro drástico en la efectividad económica y mostró débil capacidad de respuesta frente a los problemas de la sociedad (Cavarozzi 1991). En su contra irrumpen luchas sociales que rechazan las medidas de ajuste estructural y pugnan por la democratización. La emergencia de movimientos sociales en prácticamente todos los países de la región, y sus consecuencias sobre la estabilidad económica, crearon un cuadro de crisis política, lo que obligó a la revisión de las políticas globales, dando surgimiento a una «segunda generación» de reformas que buscaba la reestructuración y fortalecimiento de la organización estatal (Andara 2007).

Las organizaciones indígenas estuvieron presentes en las luchas contra las dictaduras y los gobiernos autoritarios, y fueron actores relevantes en los procesos de democratización en la región, desde la década de los setenta hasta nuestros días. Antes lo hicieron desde la trinchera del movimiento campesino clasista; más recientemente organizados como «movimientos de identidad», rechazando políticas asimilacionistas (Bengoa 2000, León 1994, Gros 2000). En sus reclamos han sido enfáticos en intentar trasformar el diseño del Estado nación monoétnico mediante reformas legales hacia el reconocimiento de sus derechos específicos, y la reconfiguración dirigida a un nuevo Estado plurinacional.

Los reclamos indígenas fueron - parcialmente- escuchados: surge una generación de reformas legales en todos los países latinoamericanos que reconocen la diversidad cultural; un ciclo de reformas constitucionales, que se conoce como «constitucionalismo multicultural» (Clavero 2002). El multiculturalismo es la nueva política desarrollada desde el Estado neoliberal que sustituye el viejo paradigma asimilacionista. Este nuevo Estado multicultural suele aceptar la representación indígena en el gobierno local siempre y cuando tenga su origen en una elección, en el marco de la democracia electoral; al mismo tiempo que demanda que los liderazgos respondan a un perfil que pueda gestionar políticas con énfasis en gerencia social. Enfoque que ha sido llamado «neoinstitucionalismo» (Nickson 2003), marco 
normativo general en el que el nuevo municipio opera, dando origen a un nuevo fenómeno al que suele llamarse «neomunicipalismo» (González s/f).

La prolongación de la incorporación de los liderazgos indígenas locales dentro de la organización estatal neoliberal mediante la figura municipal ha dado lugar a reacciones diversas entre los actores indígenas. Por un lado, la neomunicipalización es vista como empoderamiento de actores sociales indígenas, al favorecer su participación en decisiones políticas de las que antes habían sido excluidos, cuando el municipio estuvo en manos de los mestizos, principalmente. Algunos actores han pugnando por lograr una mejor inserción en la institucionalidad estatal en la lógica mencionada, intentando etnizar al nuevo municipio. Otros han rechazado ese tipo de relación, y pugnan por desarrollar nuevas estrategias que apuntan hacia la «comunalización» del gobierno indígena. Es decir, revitalizar sus propias instituciones, dentro de ellas las de los gobiernos nativos, como el Ayllu (Choque 2000), o incluso el cabildo indígena de origen colonial, rechazando la figura municipal que califican como «neoliberal». Observamos que hoy día el municipio es un campo de disputa de múltiples significaciones. Esa disputa no está resuelta y, por el contrario, en la medida en que la demanda por la reconstitución de los pueblos avanza, la figura municipal suele ser impugnada. Pero, por otro lado, en contextos en donde el municipio tiene una larga duración, allí puede constituirse como una institución apropiada. En estos contextos el «municipio indígena» es un reclamo, como parte de ese proceso de reconstitución y autonomía. De ello resultan estrategias indígenas que no lo rechazan, sino por el contrario buscan modificar su diseño y hacerlo culturalmente pertinente.

Esta lucha por significar y apropiarse del municipio como espacio para el autogobierno indígena no es un fenómeno nuevo, ha sido una estrategia recurrente en la disputa entre imposición-reelaboración-apropiación, ${ }^{3}$ en distintos momentos de la historia de larga duración de los pueblos indígenas. Esthe escrito tiene como propósito dar cuenta sobre esos procesos. Me aproximo a este esfuerzo sobre la base de tres momentos en el que se produce la municipalización del gobierno indígena y la indianización/comunalización del gobierno municipal: i) el cabildo indígena colonial; ii) el ayuntamiento gaditano y, iii) el neomunicipalismo. Comienzo con una breve definición sobre los pueblos indígenas en 
América Latina y concluyo con una reflexión sobre las estrategias indígenas para minimizar el impacto del nuevo municipio neoliberal.

\section{PUEBLOS INDÍGENAS EN AMÉRICA LATINA: UNA BREVE DEFINICIÓN}

Desde la perspectiva de los derechos humanos, son pueblos indígenas los colectivos que mantienen una continuidad histórica - real o simbólica - con las sociedades que eran anteriores a la invasión europea. Son colectivos que se asumen como diferentes de las sociedades mestizas o amestizadas de los países en los que viven; lo que permite afirmar que la asimilación colonial y poscolonial a la que fueron sometidos, no fue lograda. De acuerdo con la definición elaborada por el Relator para Pueblos Indìgenas, de la Organización de las Naciones Unidas, ONU, Alfonso Martínez Cobo (1999), los pueblos indígenas son aquellos grupos que han tomado la determinación de permanecer como sociedades diferenciadas; que mantienen la voluntad de preservar, desarrollar y trasmitir a futuras generaciones sus territorios ancestrales y su identidad étnica como soporte de su existencia continuada como pueblo, sobre la base de sus propios patrones culturales, sus instituciones sociales y sus sistemas legales.

Estas definiciones quedaron contenidas en el Convenio 169 sobre Pueblos Indígenas y Tribales (1989), de la Organización Internacional del Trabajo, OIT, en donde un pueblo indígena se define:

... por el hecho de descender de poblaciones que habitan en el país o en una región geográfica a la que pertenece el país en la época de la conquista, de la colonización o del establecimiento de las actuales fronteras estatales y que, cualquier que sea su situación jurídica, conservan todas sus propias instituciones sociales, económicas, culturales y políticas o parte de ellas.

El también relator, Rodolfo Stavenhagen (1991), incorpora el componente de la autoctonía como un elemento distintivo. Se trata de colectivos que son oriundos u originarios de las tierras que ocupan, y están allí antes de la constitución de los Estados nacionales. Así, en la actualidad, los pueblos indígenas en América Latina y el Caribe son aquellos grupos étnicos, cuya peculiaridad es descender de los pueblos originarios del territorio que ocupan (Schkolnik y Del Popolo 2005). Su permanencia se explica en la voluntad de persistir. La etnicidad es la 
fuerza que moviliza la acción colectiva de estos grupos, que hace posible su permanente reconstitución y vigencia. ${ }^{4}$

En este orden de ideas, los pueblos indígenas son construcciones históricas que tienen su punto de origen en la instauración del régimen colonial, ya que es precisamente en ese momento crucial de su historia cuando se gesta la categoría política de «indio». Guillermo Bonfil definió que lo indio da cuenta de una relación de carácter colonial. El término indio, afirma el autor:

\footnotetext{
... puede traducirse por colonizado y, en consecuencia, denota al sector que está sojuzgado en todos los órdenes dentro de una estructura de dominación que implica la existencia de dos grupos cuyas características étnicas difieren, y en el cual la cultura del grupo dominante (el colonizador) se postula como su superior. El indio es una categoría supraétnica producto del sistema colonial, y sólo como tal puede entenderse ... la presencia del indio indica persistencia de la situación colonial. Indio y situación colonial son, aquí, términos inseparables y cada uno conlleva al otro (Bonfil 1972: 117-119).
}

La independencia de los países latinoamericanos y la formación de los Estados nacionales en el siglo XIX no condujeron, sin embargo, a modificar la condición indígena; sino por el contrario, a reproducirla (Beaucage 1988). En la perspectiva de los pueblos indígenas, la situación colonial persiste ahora bajo la supremacía del grupo étnico dominante que tiene en sus manos el poder del Estado. La persistencia de esa hegemonía ha sido llamada «colonialismo interno», y da cuenta de la prolongación de la condición de «indio» de esas poblaciones (González Casanova s/f). Para superar esa situación, en las últimas cuatro décadas estos colectivos se han asumido como «Pueblos», por lo que reivindican derechos de autodeterminación política dentro de los Estados nacionales en los que viven. Derecho que aspira a ser ejercido principalmente bajo regímenes autonómicos (Díaz-Polanco 1996).

La persistencia de los pueblos indígenas se explica en la característica que esos colectivos manifiestan para reinventarse continuamente. Han mostrado una fuerte capacidad para reconstituir y significar permanentemente sus instituciones; entre ellas sus instituciones de gobierno. Así, aunque su institucionalidad se represente como antigua o ancestral, estas son siempre contemporáneas. 


\section{LOS MOMENTOS DE LA MUNICIPALIZACIÓN DEL GOBIERNO LOCAL INDÍGENA}

Aquí se sostiene que los llamados «gobiernos indígenas» son construcciones históricas resultado de una compleja mixtura amasada con componentes que provienen de las instituciones de gobierno nativo y aquellos formados por el orden colonial, primero, y por los Estados nacionales, después. El «gobierno indígena» es un resultado histórico producto de un diálogo tenso entre los pueblos indígenas y los distintos intereses y tensiones que lo cruzan, tanto hacia adentro como con otros diálogos, alianzas, presiones y disputas, que sostienen con actores externos; entre éstos con las instituciones estatales, en sus distintos momentos históricos. El municipio ha sido una institución clave en los procesos de configuración del gobierno indígena; de hecho, podemos afirmar que la voluntad gubernamental ha sido la de municipalizar al gobierno indígena, pero este se ha configurado en resistencia, marcando siempre la diferencia. Para adecuarse a los cambios en el Estado — que ha pasado de colonial, a republicano, a nacional-popular, a neoliberal-multicultural, y ahora -en Bolivia- a plurinacional-posneoliberal- las instituciones de gobierno indígena han sido de igual manera siempre cambiantes.

En las páginas siguientes vamos a aproximarnos a los cambios en la institución municipal estatal y a la voluntad gubernamental de municipalizar los espacios de gobierno local indígena; y frente a esto los esfuerzos de los pueblos indígenas por indianizar/comunalizar y significarlos como "propios", como "gobierno indígena".

\section{LA PRIMERA MUNICIPALIZACIÓN}

El gobierno indígena en América Latina surge en el paso crucial del sistema político prehispánico a la vida del Estado colonial español. Antes que el régimen colonial se estableciera la categoría de «gobierno indígena» no existía, toda vez que la condición de «indio» o «indígena» no estaba instaurada. Desde su origen, el gobierno indígena no ha sido una institución política independiente que regule las relaciones de poder de un grupo nativo local aislado. Por el contrario, ese se ha constituido como resultado de un sistema de interrelaciones sociopolíticas, cuyos elementos de organización, ideología y control, se usaron para administrar y controlar el orden de su propia existencia cultural, así como, y sobre todo, para enfrentarse a diversos contextos de interrelación a los que desde entonces han estado 
expuestos (Burgos 1995). El gobierno indígena fue constituido por los propios colonizadores, quienes no destruyeron sino que usaron a su favor el orden de cosas existente. Reestructuraron las antiguas instituciones y jerarquías del gobierno nativo para organizar la vida colonial, produciendo una resignificación y acomodo de las antiguas jerarquías. El Cabildo de Indios fue delineado sobre los patrones de organización prehispánica. ${ }^{5} \mathrm{Al}$ nacer, el gobierno indígena modificaría las nociones, funciones y jerarquización del gobierno nativo prehispánico; estableciendo algo nuevo que serviría al orden colonial. De sus nuevas funciones establecidas destacan la recolección del tributo y la organización de la mano de obra, así como la gobernabilidad local (Aguirre 1952).

Otra consecuencia fue la modificación del carácter abarcador del gobierno nativo —que incluía distintos niveles - y su reducción a la escala local. Los estudiosos de la zona andina han documentado la importancia de la interrelación económica y política que existió entre los pisos ecológicos en la historia del Estado Inca. Murra (1983) desarrolló la hipótesis de la existencia de un sistema político establecido en niveles territoriales discontinuos, articulados políticamente, a los que llama «archipiélagos verticales», que funcionó como un sistema político para la apropiación de los distintos espacios andinos. Ese gobierno nativo fue desarticulado. Al reconfigurarse como «gobierno indígena» quedó reducido a su carácter local en un archipielago de gobiernos locales. El orden colonial no permitió a los indios el acceso a los puestos directivos de la colonia, y sólo les concedió un gobierno local semiautónomo, modelado conforme a una institución occidental: el municipio español, con su propio ayuntamiento. La República de Indios y el Derecho indiano, en lo general, estructuraron nuevas instituciones de gobierno indígena en lo que sería América Latina. Es por ello que la mayoría de los gobiernos indígenas en la región comparten rasgos comunes, independientemente de su especificidad lingüista y su distancia entre sí. La legislación colonial, que fue vigente para todo el naciente subcontinente iberoamericano, los unificaba bajo una única categoría étnico política, de lo que resultaron los rasgos compartidos de las instituciones del gobierno indígena.

En tiempos tempranos de la colonia se comenzó a legislar sobre las instituciones de gobierno que tendrían los indígenas. Para el caso de México, inicialmente se les había llamado caciques, adoptando la denominación nativa antillana. Poco a poco fue sufriendo 
adecuaciones. Por cédula del 26 de febrero de 1538 dirigida a la Audiencia de México, se dispuso que ya no se les llamara «señores de los pueblos o municipios en que presiden, sino sólo Gobernadores o Principales» (Chávez 1943: 5). Tomando como base el modelo español, en 1555 la autoridad indígena se integraba por dos alcaldes y doce regidores. En 1675, las autoridades indígenas en la ciudad de México eran: gobernador, alcalde, regidores, alcalde ordinario, regidor mayor, alguacil mayor, regidor mayor, escribanos.

Otro rasgo distintivo de los pueblos indígenas fue el esfuerzo continuo por resignificar las instituciones españolas. Así, aunque los nombres de los cargos eran los mismos que los de la República de Españoles, esos fueron recurrentemente adecuados a los códigos culturales nativos; lo que explica su rápida apropiación — por «indianización»—. Por ejemplo, para acomodar los cargos dentro del mundo nahua hubo que cambiar su significado. Al estudiar la instauración del Cabildo español sobre la institución del «altépetl» nativo entre la población nahua de México, Lockart (1999) identifica algunas de esas adecuaciones:

a) En el municipio español, era necesario contar con un núcleo o cabecera. No lo era así en el altépetl, en donde la población vivía dispersa en los calpulli; por lo que al menos en la primera etapa (hasta finales del siglo XVIII), el núcleo o cabecera municipal no tuvo mayor relevancia;

b) La figura del gobernador en España era una suerte de corregidor. Ésos regularmente se entendían como figuras que representaban los intereses de la Corona, por lo que eran personas extranjeras o extrañas dentro de los territorios que gobernaban. No sucedió así en el área nahua. Con la oposición primero, pero con la aceptación después, los gobernadores indígenas gobernarían sus propios lugares de origen, refrendando las funciones del tlatoani, que sólo cambió de nombre;

c) En el municipio-altépetl los cargos de regidor y alcalde fue necesario que tuvieran una representación territorial de las partes que integraban el altépetl.

Una consecuencia de esta adecuación fue que el número de miembros que integraba el cabildo indígena fue siempre mayor que el total que integraba la institución española. Fue usual multiplicar el número de alcaldes más allá de dos, como les marcaba la norma española. También fue frecuente crear un grupo grande de regidores con representación territorializada de las unidades que lo integraban. En Tlaxcala, México, el cabildo (1545) se integró con cuatro alcaldes, uno por cada altépetl constitutivo; por cuatro tlaloque, que desempeñaban el cargo de regidores perpetuos — como marcaba la norma española—. Además crearon tres 
nuevos regidores que cambiaban cada año por cada altépetl; entre otras adecuaciones del mismo signo. En la opinión del autor,

...está claro que los nahuas igualaron, en un sentido general, la estructura y los cargos sociopolíticos de antes de la conquista con los del periodo que la siguió, y hubo supervivencias significativas de un periodo al otro. Es más, el grado de continuidad fue crucial para el establecimiento rápido y venturoso de gobiernos municipales que funcionaran independientemente de toda la región, algo que en muchas partes de la América hispánica ocurrió más tarde o no se llegó a presentar (Lockart 1999: 62).

La instauración de las nuevas instituciones del gobierno indígena no se realizó de manera tersa, sino con resistencias y disputas constantes entre los diversos actores, tanto desde el campo de los españoles - la clásica disputa entre iglesia y corona-, así también como en el terreno de los propios colectivos indígenas. Los grupos disputantes por lograr ocupar los cargos del poder local buscaban sostener su legitimidad, y algunos apelaban a las normas y regulación ancestral —a la que desde entonces se les llamó «usos y costumbres»-, rechazando la intervención de los colonizadores; y otros al nuevo orden. En el periodo colonial hubo rebeliones en contra de los españoles; también las hubo en contra de las autoridades indígenas (Chávez 1943). Al paso de los siglos, el Cabildo de la República de Indios fue progresivamente significándose como una institución apropiada. En dos siglos, entre el XVI y el XVII, la República de Indios había sido «indianizada».

Pero un nuevo ciclo se abre con las reformas borbónicas, lo que tuvo la consecuencia de modificar ese acomodo, motivo por el cual hubo frecuentes levantamientos en diversas regiones de la naciente América Latina. Fueron emblemáticas las de Túpac Amaru y Túpac Catari en la zona andina (Chiaramonti 2007). El siglo XVIII se presenta como un periodo de reestructuración política y una redefinición de las instituciones coloniales, creando nuevas identidades (Menegus 1996). El régimen de intendencias se aplicó a partir del siglo XVIII en las posesiones del Imperio Español en América y las Filipinas, introduciendo cambios relevantes en las instituciones de gobierno indígena. De lo más relevante fue el desplazamiento, hasta casi aniquilamiento, de las autoridades indígenas de «tipo señorial». Se trataba de «caciques»o señores que habían colaborado con los españoles, por lo que obtuvieron reconocimiento parcial por su jerarquía. Sus descendientes permanecieron cobrando tributos en ciertas áreas que reclamaban como espacios de jurisdicción. En el resto 
de las regiones indígenas, en donde los cacicazgos no permanecieron, se estableció la organización castellana del municipio bajo el gobierno de los cabildos, con sus alcaldes, como ya se ha mencionado arriba. El cambio de régimen a Intendencias favoreció la expansión de los cabildos gobernados por alcaldes. Serían éstos, y no ya los caciques, quienes tendrían los territorios indígenas bajo su jurisdicción (Sala 1992). A lo largo del siglo XVIII el alcalde de indios cobró, de forma lenta, un mayor protagonismo, creando tensiones en donde el poder de los caciques mantenía cierto peso.

El siglo XVIII tuvo consecuencias diversas. Carmagnani (1988) evalúa que en ciertas regiones de México, al entregar el gobierno local al común de la gente, los cabildos indígenas se fortalecieron. Destaca que durante ese periodo los mixtecos y zapotecos de Oaxaca se reconciliaron con sus dioses al recuperar su religiosidad. Este proceso fue posible porque los cabildos indígenas se fueron construyendo durante el siglo XVIII como espacios semiautónomos. Mediante el cabildo, los grupos étnicos oaxaqueños reestructuraron su etnicidad reforzándola. Fueron factores detonantes a esos cambios las rebeliones indígenas, como la que protagonizaron los zapotecos de Tehuantepec (Díaz-Polanco y Burguete 1996). Al final del siglo XVIII florecieron varias decenas de cabildos indígenas, desde México hasta la zona andina. No sin presiones, en el curso del periodo colonial, el cabildo había vivido procesos de «indianización»; al mismo tiempo que el gobierno indígena se municipalizaba, creando un tipo de gobierno indígena local que era cada vez más lejano al diseño de la República de Indios establecida por la norma colonial, pero también muy distinta de lo que habían sido los gobiernos nativos. Una nueva forma de «gobierno indígena» había nacido.

Sin embargo, las cosas darían un giro radical en el siglo XIX, como resultado de varias modificaciones en la institución municipal, que arribaría en el contexto de la efímera - pero de consecuencias duraderas - Constitución de Cádiz (1812-1814, 1820-1823) y los nuevos ayuntamientos gaditanos. ${ }^{6}$ Al curso del siglo XIX los cabildos indígenas dejarían de tener reconocimiento legal. Nuevamente hostigado, el gobierno indígena permanecería en la clandestinidad, cobijado bajo la denominación de «usos y costumbres». 


\section{LA SEGUNDA MUNICIPALIZACIÓN}

Entre 1808 y 1812, las provincias y las ciudades del imperio español formaron Juntas Gubernativas en respuesta a la invasión de Napoleón Bonaparte sobre la península española. La llamada «revolución liberal» en la península ibérica trajo cambios profundos en la organización y gestión de la metrópoli y sus posesiones de ultramar. La Constitución de Cádiz - gaditana - de 1812 incorporó una nueva concepción del territorio y de las formas de organizarlo y ordenarlo, desarrollando nuevos conceptos como una mayor centralización y dependencia de los componentes del sistema territorial. En la Constitución, el territorio se organizó en dos ejes fundamentales: las provincias y los ayuntamientos, uniformando a todo el reino, como estrategia para hacer más eficaz la recaudación fiscal; incluyendo además la representación. Las provincias se convirtieron en unidades de gobierno, además de que cada conglomerado de mil o más habitantes podría adquirir el rango de municipio, mismo que debía ser encabezado por un ayuntamiento electo por los ciudadanos. En México se formaron más de mil municipalidades, algunas de ellas en poblados indígenas (De Gortari 1997). El tránsito de gobierno indígena a ayuntamiento se vivió de manera diferenciada según el contexto histórico-regional (Escobar 1996, Palomo 2009).

En muchos casos, los nuevos ayuntamientos constituidos en poblados indígenas produjeron una acelerada desindianización del gobierno local. La Constitución gaditana reconoció a todos los habitantes de la península y de ultramar la condición de ciudadanos, buscando disolver los identificadores étnicos, propios del periodo colonial. Como consecuencia, los ayuntamientos en las regiones indígenas pasaron a ser disputados por personas de distintas categorías étnicas que vivían en las regiones indígenas; que para entonces ya eran étnicamente diversas. Esta tendencia de desplazamiento de los indígenas del ayuntamiento se refrendó años después, cuando irrumpen las revoluciones de independencia en las posesiones de ultramar — en la década de los veinte del siglo XIX-, dando origen a los Estados nacionales. La independencia se tradujo en el triunfo político de criollos y mestizos, quienes desplazaron a los españoles de los puestos de alto nivel, y a los indígenas de los gobiernos municipales.

En muchos lugares los indígenas vieron - y participaron - en las luchas de independencia como una oportunidad para recuperar el autogobierno; pero los tiempos de ideología liberal no favorecían esos proyectos. Espinosa (2007) relata el episodio de petición de los incas del 
Perú para la restitución del gobierno originario de esas tierras, después de la independencia de España. Menciona que la población criolla de la ciudad de Cajamarca en Perú, capital de la provincia de mismo nombre, juró su independencia el día 8 de enero de 1821. Al tomar conocimiento, la nobleza indígena de la localidad concurrió para plantear que el gobierno del nuevo Estado debía corresponder a un descendiente de Atahualpa que viviera en el vecindario; pero nadie dio respuesta a esta argumentación. Desplazados del poder de arriba aspiraron, por lo menos, a conservar los poderes provinciales y disputar a los criollos y mestizos pobres el «asalto al poder local» que ya realizaban. Este es un rasgo común que comparte el gobierno indígena en América Latina. Desplazados de los gobiernos nacionales, lo local es el espacio en donde el gobierno indígena se ha construido en medio de una fuerte disputa. Sobre cómo esta ocurrió en el Perú, Sala (1992) abunda:

El Cabildo indígena, al defender un gobierno étnicamente diferenciado, reconocía su derrota e incapacidad para hacer frente al papel preponderante de los sectores mistis [mestizos] en la zona. Lejos de reclamar la igualdad, en clara posición de repliegue, solicitó que se acentuara la protección real, que les garantizara el acceso a la tierra y un gobierno propio. El caso nos muestra a un sector indígena que, aun tomando conciencia de la raíz de su situación, al considerar inviable su coexistencia en igualdad de condiciones con sectores mestizos y blancos, optó por defender la persistencia de la República de indios aislada de los otros sectores étnicos, seguir aliado con la Corona hispana, en cuanto ésta le pudiera garantizar su defensa ante la progresiva intromisión de elementos foráneos tanto en su gobierno como en su economía (Sala 1992: 66).

Igual situación se vivió en las regiones indígenas de México. En el nuevo marco jurídico, muchas antiguas Repúblicas de Indios no pudieron cumplir los requisitos que la ley establecía. Bajo el régimen colonial, para que un pueblo de indios pudiese erigirse en gobierno autónomo debía tener 80 tributarios —alrededor de 360 habitantes-. En 1826, los 220 pueblos que había en la mixteca oaxaqueña tenían en promedio 340 habitantes; promedio correspondiente a las 87 sedes de gobierno municipal que había entonces en esa región. Sólo media docena contaba con una cabecera municipal con los mil habitantes o más que la nueva legislación requería para que esos pueblos pudieran ser reconocidos como municipios. El resultado fue que 74 pueblos perdieron su estatuto de autogobierno, quedando como dependientes —agencias municipales- de las nuevas municipalidades gaditanas. 
Adicionalmente, en la mayoría de ellas el ayuntamiento quedó en manos de mestizos (Pastor 1987: 420-421).

En resumen, con la nueva municipalización gaditana el cabildo indígena, y con ello el autogobierno indígena, perdió su reconocimiento oficial. Por esta situación, el proceso de reconstitución étnica logrado en el siglo XVII y XVIII en las zonas mixteca y zapoteca se vio drásticamente frenado por el ascenso del poder criollo y mestizo. En la opinión de Carmagnani (1988), a partir del siglo XIX se produjo en esa región una nueva, o segunda «conquista»: los grupos étnicos oaxaqueños - $\mathrm{y}$ en general los mexicanos, y todos los pueblos indígenas en donde se constituyeron las nuevas repúblicas - quedarían colocados en una situación «neocolonial».

\section{LA INDIANIZACIÓN DEL MUNICIPIO GADITANO}

En el siglo XIX la nueva estrategia de resistencia indígena trabajaría con el objetivo de ir a la conquista del municipio gaditano; para llegar a ello tuvo que enfrentar diversos retos. Al paso del siglo XIX la negativa de reconocer al gobierno indígena como una categoría jurídica específica fue contundente. El discurso liberal de la igualdad ciudadana le colocó en la clandestinidad, cuando cuerpos de autoridades indígenas permanecieron en las pequeñas localidades, aunque sin relevancia política, toda vez que ya no tenían el reconocimiento oficial. El gobierno indígena permanecía oculto.

Los antropólogos que realizaron monografías en las comunidades indígenas durante los dos primeros tercios del siglo XX, los encontraron funcionando mediante una modalidad a la que dieron el nombre genérico de «sistemas de cargos» (Korsbaek 1996), «autoridades tradicionales» (Prockosch 1973) o «autoridades de usos y costumbres» (Velásquez 2000). Pese a esa falta de reconocimiento —o quizá por ello—, conforme trascurría el siglo XIX las comunidades y municipios indígenas fueron resignificando las nuevas instituciones del gobierno republicano, al apropiarse de algunos espacios de poder. Este proceso silencioso solo pudo ser visto hasta que las investigaciones de principios del siglo XX mostraron que las identidades étnicas correspondían a jurisdicciones municipales, y que los gobiernos municipales eran con frecuencia gobiernos indígenas. 
En Guatemala, por ejemplo, los municipios se constituyeron en el siglo XIX sobre la base de las divisiones étnicas básicas, asumiéndose cada uno como la base identitaria de cada grupo sociocultural de la diversidad étnica del país; según observó Tax (1996) en las primeras décadas del siglo XX. El municipio adquirió tal importancia en las configuraciones étnicas de finales del siglo XIX que los gentilicios aplicados a los indígenas de los diversos municipios y reconocidos por todos los demás, así como por ellos mismos, eran tomados de los nombres de los propios municipios al estilo español. De este modo una persona nacida en Quetzaltenango era nombrado y se auto adscribía como un quetzalteco; uno de Totonicapán, totonicapeño. Adicionalmente, junto con el gentilicio, se distinguían por el vestido, que era distinto al de los otros municipios de su entorno. En las primeras décadas del siglo XX, típicamente cada municipio tenía un traje para los hombres y uno para las mujeres, por lo que era elemento de clasificación. La indianización del municipio durante todo el siglo XIX, y primer tercio del siglo XX, hizo posible otra vez la configuración de nuevas territorialidades étnicas, así como la reinvención del autogobierno indígena.

Pero, de nuevo, aires modernizadores intentarían romper ese equilibrio logrado entre territorio, identidad, gobierno indígena y municipio. Nuevos esfuerzos integracionistas desplegados en los dos primeros tercios del siglo XX volverían a intentar desestructurar a los «municipios indígenas» que se habían configurado. Los gobiernos nacional populares que buscaban la integración nacional en las primeras décadas del siglo XX promovieron la disolución de las identidades de los pueblos indígenas. La asimilación de sus formas de gobierno propio fue vista como parte de esta estrategia política. En México, Gonzalo Aguirre Beltrán (1991), antropólogo indigenista, visibilizó la importancia de que el «municipio libre» -el municipio constitucional del México posrevolucionario- tendría en la cruzada integracionista. Lo dijo con las siguientes palabras:

Esta integración ha sido una de las motivaciones vehementes de la Revolución ... Una de las medidas de mayor trascendencia fue la de otorgar a las comunidades [indígenas] una autonomía de gobierno dentro de los módulos generales fijados por la Constitución al regir el municipio libre. La mayoría de las comunidades indígenas, su gente y el territorio que ocupa, constituyen en la actualidad municipios libres (Aguirre 1991: 17). 
El autor no ignoraba que la instauración del municipio libre tenía la consecuencia de eliminar a los gobiernos indígenas considerados como «propios» por los pueblos indígenas. En sus palabras:

La Revolución, no obstante el aparente fracaso del municipio libre en estas comunidades, sostuvo como meta invariable la forma de gobierno por ella elegida y negó a dichas comunidades el derecho a gobernarse conforme a sus patrones tradicionales. Esta política puede parecer incongruente a quien ignore que el movimiento revolucionario de México persigue como objetivo primordial la integración de una comunidad nacional en que todos sus miembros participen de los beneficios de una cultura común. Al contradecir la ficción liberal de la igualdad de los mexicanos la Revolución sacrificó, además, el principio de libre determinación de los pueblos para regirse conforme a sus propios patrones, pues consideró más valiosa meta la consecución de la unidad nacional como requisito ineludible en el logro de un progreso efectivo y de un modo de convivencia mejor (ibídem, pp. 55-56).

Esta tendencia no se modificó durante todo el siglo XX. Por el contrario, regímenes autoritarios del Estado nacional popular impusieron de manera vertical la institucionalidad estatal mediante políticas autoritarias de integración (Robles 2002). En México, el municipio fue también en esa ocasión terreno de disputa. De esta manera se le vio como un espacio democrático para la realización de los derechos de ciudadanía; no fue circunstancial que a la institución municipal que naciera con la nueva Constitución de 1917 se le llamara «municipio libre» (Chevalier 1989). Se recuerda que durante casi setenta años el PRI intervino para seleccionar a los miembros de los concejos municipales en las regiones indígenas, de tal forma que respondieran a los intereses gubernamentales, haciendo del «municipio indígena» una institución funcional a los intereses gubernamentales. Este fenómeno fue estudiado por Rus (2004) en el municipio de Chamula, región Altos de Chiapas. El autor observó que aunque el «gobierno indígena» se mantenía, el perfil de los funcionarios en el ayuntamiento municipal había sido cambiado, respondiendo a los esfuerzos integracionistas del México posrevolucionario.

Por esta intervención directa del Estado mexicano en el funcionamiento del gobierno local constitucional fue frecuente que en los pueblos indígenas del altiplano chiapaneco $-\mathrm{y}$ como tendencia general - permanecieran vigentes dos instituciones de gobierno local indígena: la del viejo cabildo — el llamado «gobierno tradicional»o de «usos y costumbres»—, que se 
encargaba de la gobernabilidad interna y de su comunicación con los dioses ancestrales; la del ayuntamiento municipal constitucional, que se hacía cargo de los vínculos con el exterior, y con las instituciones del gobierno federal y del Estado.

Así se llegó al final del siglo XX, en creciente proceso de debilitamiento del cabildo indígena y del gobierno comunal, que parecía fenecer. Hasta que la rebelión del Ejército Zapatista de Liberación Nacional, EZLN, y la expansión de las luchas autonómicas en el Continente; así como la instauración de un nuevo diseño de Estado plurinacional en Bolivia (Albó y Romero 2009), volvieron a dar un nuevo respiro al antiguo - siempre nuevo- gobierno indígena.

\section{NUEVA MUNICIPALIZACIÓN DEL GOBIERNO INDÍGENA EN TIEMPOS DE REFORMAS NEOLIBERALES}

En la coyuntura que se abre en los años ochenta del siglo XX, en un contexto de reformas del Estado, con el surgimiento de luchas de autodeterminación indígena, el gobierno local indígena y la institución municipal viven nuevos procesos de resignificación. El municipio es en la actualidad un espacio en el que se disputan múltiples significados de gobierno indígena.

Pese a la ambición integracionista, las políticas indigenistas del siglo XX no fueron consistentes. En la mayoría de los países latinoamericanos la presencia estatal en las regiones indígenas fue débil o muchas veces estuvo ausente, y regularmente las intervenciones de mayor impacto fueron las políticas de reparto agrario, con enfoques campesinistas. La ausencia del Estado en esas regiones se agravó en los años ochenta, como resultado de las políticas de liberalización económica y política, y por el ajuste estructural. En este contexto irrumpen luchas indígenas que protestan contra los gobiernos autoritarios y pugnan por superar la exclusión. Un naciente movimiento indígena demanda políticas de reconocimiento, autonomía y autogobierno (Sánchez 1999).

En los años ochenta y noventa del siglo XX, la mayoría de los países de América Latina vive procesos de democratización; en este contexto, se realizan reformas constitucionales que reconocen la diversidad cultural como parte constitutiva de sus sociedades, así como políticas de reconocimiento. Esta combinación entre pluralismo étnico y pluralismo político hace posible que los indígenas puedan ascender al poder local; incluso irrumpen en niveles antes 
inéditos. Van más allá de la comunidad y el municipio, o incluso gobiernan a otros no indígenas (Lalander 2005). En las últimas dos décadas, indígenas gobiernan municipios pluriétnicos - de coexistencia indígena y no indígena- en Guatemala, Ecuador, Bolivia, Chile, México y Perú; así como en los niveles meso, como las prefecturas —en Ecuador y Bolivia-. E incluso ascienden a cargos del ámbito nacional, ocupando puestos como vicepresidente, en Bolivia, y presidentes en Perú y Bolivia. Todo ello con un cierto éxito que se ha reflejado en experiencias de reelección (Burguete 2008).

Simultáneamente, una de las dimensiones de la reforma del Estado en América Latina en las últimas tres décadas fue la municipalización de la organización político territorial. Políticas de democratización y participación colocaron al municipio en el centro de la intervención pública; lo que ha dado lugar a la municipalización de las políticas públicas, así como a la reorganización político territorial, al dar nacimiento a nuevos municipios. Los actores ven allí una oportunidad para el empoderamiento. En contextos indígenas irrumpen liderazgos que asumen la representación política con demandas de identidad, etnizando la política y politizando la cultura. En varios de esos municipios las autoridades locales se asumen como gobierno indígena, abriendo la oportunidad para hacer caminar agendas indígenas.

El nuevo Estado reformado respondía, simultáneamente, a las presiones de la expansión del capitalismo trasnacional. La democratización requería autoridades locales eficientes y atentas a regulaciones, orientadas por nuevas teorías de la administración pública del New Public Management, inspirada por los métodos de gestión empresarial dictada por los enfoques del neoinstitucionalismo, que buscaban la «gobernanza local» (Nickson 2003, Assies 2003a). Ser indígena ya no fue un impedimento para ascender al gobierno local en las democracias multiculturales que nacían en la última década del siglo XX. Siempre y cuando las nuevas autoridades municipales arribaran al poder mediante procesos electorales y el perfil de los liderazgos pudiera responder a los lineamientos de la administración municipal con enfoque neoinstitucional. En los últimos tiempos esas autoridades se asumen como «gobierno indígena», en municipios con alta presencia indígena (Burguete 2008). Pero, no todos coinciden en su valoración. Diversos actores indígenas rechazan esos procesos de municipalización, mientras que otros lo ven como oportunidad para el empoderamiento, e 
incluso el autogobierno indígena. Los ejemplos de municipalización en Chile, Bolivia y Venezuela, nos permitirán acercarnos a esas dinámicas y debates.

\section{MUNICIPALIZACIÓN EN CHILE}

En Chile, el municipio adquirió especial importancia en las reformas económicas introducidas durante la dictadura de Augusto Pinochet (1973-1990). Los municipios fueron espacios para viabilizar las reformas económicas que la nueva fase del capitalismo neoliberal demandaba, así como la base de poder para su implementación (Mardones 2006). En el periodo pinochetista se observan procesos de municipalización en todo el territorio nacional, en dos sentidos: por un lado, haciendo funcionales a los nuevos municipios que ya existían, adecuándolos al nuevo diseño del Estado y economía. Por otro lado, creando nuevos municipios, haciendo de la institución municipal un recurso para la reorganización del Estado. Siete nuevos municipios fueron formados en 1996, mientras que entre 2000 y 2004 se crearon otros cuatro.

La neomunicipalización en Chile, esto es, su trasferencia de prerrogativas, recursos y nuevas atribuciones, fue inicialmente una estrategia de desconcentración (Gundermann 2007). El impulso de desconcentración a escala local en Chile no siguió una pauta progresista, sino que combinó un principio neoliberal de reducción del Estado con criterios tecnocráticos, que buscaban un aumento de eficiencia en la provisión de servicios - lo principal salud y educación, en niveles básicos_-, entregando nuevas funciones a los municipios. Sólo más tarde, con la democratización iniciada durante la década de 1990, esos cambios tomaron la senda de reformas de descentralización — de la segunda generación de la reforma del Estado- en donde las exigencias de democratización fueron un factor relevante, como por ejemplo las reformas de 1992 relativas a la elección de alcaldes — presidentes comunales - y concejales - munícipes-. En ese proceso de democratización, el voto adquiere un nuevo valor, haciendo posible que indígenas asciendan al gobierno local.

Sin embargo, la municipalización y la reorganización territorial asociada no se realizó en Chile al tomar en cuenta a los pueblos indígenas como grupos sociales pertinentes para la definición de unidades territoriales comunales; salvo de manera fortuita como en Isla de Pascua. Las definición de las jurisdicciones municipales omitió la impronta municipal de las 
pasadas configuraciones municipales. Más bien al contrario, dada la condición de proximidad de esos colectivos a las zonas de frontera - Perú, Bolivia y Argentina-, en donde se concentraba población indígena, el Estado había mostrado resistencia a formar municipios y a entregar la gestión en manos locales. Fue hasta la década de los noventa que la municipalización se extendió hacia esas regiones, pero sin que se inscribieran en la lógica de reconocimiento de territorialidades indígenas, sino en la «modernización de las reducciones indígenas» instaladas desde finales del siglo XIX, como un recurso funcional para el Estado que sustituyera la vieja forma de relación entre el Estado chileno y los pueblos indígenas (Foerster 2007). En lo general, las comunas fueron establecidas según principios de definición por unidad territorial y funcional —unidad geográfica relativa, volumen de población, comunicaciones y accesibilidad-, y no sobre la base de la territorialidad étnica. Una comuna - municipio, en Chile - es un centro o cabecera político administrativa con características urbanas — ciudad pequeña o mediana, a veces pueblo - a la que se vincula un sistema de localidades y sectores rurales.

Pese a la carencia de voluntad gubernamental de reconocimiento de derechos, el proceso de «municipalización de los espacios étnicos» en Chile adquirió en tiempos de multiculturalismo connotaciones étnicas. Por ejemplo, en la región andina del norte de Chile la municipalización introdujo nuevas e inéditas dinámicas, favorecidas por el apuntalamiento de la minería y por la mayor integración nacional, resultado de nuevas vías de comunicación; con una mayor presencia de las instituciones nacionales. Entre otros se creó un nuevo escenario que modificó la organización social y las identidades. La instauración de los nuevos municipios en las regiones andinas de Taracapacá y Antofagasta introdujo de igual manera cambios, entre los que destacan el tránsito de «microrregiones campesinas» hacia la regionalización de una sociedad andina, que dibuja sus contornos con componentes étnicos (Gundermann 2004).

La municipalización abrió una nueva coyuntura para los actores locales, favorecida por la revitalización del espacio municipal como resultado de las políticas de participación popular. La democracia electoral en la elección del gobierno local abrió la oportunidad para el juego político, lo que dio lugar a nuevos sujetos en este ámbito. Como consecuencia de las anteriores combinaciones, propias de finales del siglo XX y primera década del siglo XXI, los municipios constitucionales ubicados en regiones indígenas suelen estar gobernados por 
indígenas; sin que incluya el reconocimiento a las instituciones de gobierno indígena asumidas como ancestrales, dando lugar a un nuevo tipo de gobierno indígena, que comenzó a ser identificado con ciertos emblemas simbólicos que buscaban legitimidad en referentes ancestrales.

Los actores que intervienen en las luchas por el control del poder local y en la gestión municipal hacen intervenir lógicas andinas y reglas del juego locales nuevas, así como factores, fuerzas, intereses y condiciones normativas externas. A una política local que se complejiza aceleradamente corresponden, entonces, sujetos andinos que se ven impelidos a adquirir capacidades sociales y culturales para actuar ventajosamente en tales escenarios para, se presume, favorecer a los propios, en un contexto de políticas indígenas por aumentar el control sobre la jurisdicción etnizada.

Al referirse al proceso de municipalización de las zonas andinas del norte de Chile, Gundermann (2004) advierte que el no reconocimiento a las instituciones de gobierno local y a sus propias formas de elección y nombramiento de autoridades es una de las limitaciones más visibles en ese país. No obstante se ha abierto la oportunidad para la irrupción de un nuevo tipo de gobierno municipal, así como nuevas formas de liderazgos locales como partícipes de la política local e incluso como organizadores de ella. En la perspectiva del autor, la base social de la municipalización del espacio andino no es una sociedad tradicional, sino una sociedad dinamizada por su inserción a la economía de mercado. Las sociedades andinas de inicios del siglo XXI son considerablemente más heterogéneas y complejas que en el pasado.

Al nacer el nuevo siglo, el municipio es un espacio en disputa en donde las luchas por la identidad pueden dar nuevos sentidos a las instituciones de gobierno local -mediante complejos procesos de etnizacion del espacio público-, ahora ajustadas a la lógica del neoliberalismo.

\section{MUNICIPALIZACIÓN EN BOLIVIA}

El caso boliviano es paradigmático. En el año 1994 este país tenía sólo una veintena de municipios, con una institucionalidad débil y localizada principalmente en las zonas urbanas. 
Pero una nueva Ley de Participación Popular, LPP, ${ }^{7}$ emitida en el marco de un ambicioso programa de Reforma del Estado, implementado durante el periodo de gobierno del presidente Gonzalo Sánchez de Lozada (1993-1997), favoreció una política de descentralización que incluía como componentes la creación de tres centenas de municipios, y políticas de participación. Antes de la reforma, el ordenamiento territorial era conformado por: departamentos (9), provincias (112), secciones de provincias $(301)$, cantones $(1,408)$. Los departamentos y las provincias contaban con un prefecto y un subprefecto, respectivamente; ambos designados por el nivel de gobierno superior —es decir, nacional y departamentalLas secciones no contaban con un órgano de gobierno reconocido, aunque era allí en donde se refugiaban, de manera clandestina, las viejas instituciones del gobierno indígena: el cabildo, los ayllus, las markas, como gobierno de las comunidades. En los cantones existían corregidores que fungían como delegados de la subprefectura, así como agentes municipales electos por la población. En las capitales de provincias existían los alcaldes municipales. La base de la municipalización de LPP estaba constituida por las secciones provinciales — es decir, las comunidades - que fueron convertidas en municipios, creándose 200 nuevos municipios urbano rurales. Adicionalmente, otros viejos municipios se «reformaron», haciéndolos funcionales a la nueva lógica del Estado neoliberal. La suma de todos ellos alcanzó un total de 311 «nuevos municipios» (Assies 2003).

La LPP fue polémica y muy cuestionada, a grado tal que en Bolivia se le conoció como «la ley maldita», así le llamaron algunos dirigentes de las organizaciones campesinas y sindicales del altiplano y valles (Albó 2002); y se subraya en el origen vertical de la propuesta: «...la municipalización era todo menos una demanda social»; la municipalización fue más bien una «necesidad del Estado» (Assies 2003: 138). Era parte de un proyecto internamente coherente de reformas modernizadoras de corte neoliberal, que proporcionaba un nuevo marco institucional para la provisión de servicios estatales de forma más eficiente. La LPP promovió y consolidó una forma específica de participación popular que articulaba a las comunidades indígenas, campesinas y urbanas, en la vida jurídica, política y económica. La inclusión de la población indígena a la institucionalización del Estado formaba parte de un proceso de disciplinización en torno al municipio y a un tipo de democracia: la liberal representativa. Para Assies: 
El proceso de municipalización implicó la imposición por parte del estado de un patrón homogéneo sobre una realidad social sumamente heterogénea con consecuencias importantes para uno de los grupos supuestamente beneficiados por la Ley de Participación Popular: los pueblos indígenas. Puesto que hasta la promulgación de la Ley de Participación Popular el municipio era virtualmente inexistente en el país esta entidad tampoco existía como referente de identidad. Para los pueblos indígenas las referentes de identidad a menudo son el ayllu, la capitanía, etc. Para la población indígena-campesina el sindicato es una referente importante. La introducción de los municipios, a su vez subdivididos en distritos y cantones como base ideada para las OTBs, resquebraja estas formas de sociabilidad y de organización socio-política (Assies 2003: 148).

Sin embargo, la institucional estatal no «bajó» de manera acrítica, sino que fue sometida a un proceso de apropiación realizado de manera reflexiva. Por esta estrategia, esas reformas fueron el origen de un profundo cambio en el camino hacia el empoderamiento comunitario y hacia el reconocimiento de los derechos de los pueblos indígenas, así como hacia la construcción de una nueva institucionalidad en la organización político territorial del Estado. Sin proponérselo, la figura municipal dotó a las comunidades indígenas de un instrumento para intervenir en la vida local y regional, ampliando su presencia en donde antes no había estado. Y como ocurrió en Chile, los actores locales aprovecharon la oportunidad de tener en sus manos las instituciones estatales y procedieron a su resignificación, incluso en algunos lugares a la indianización de esas instituciones.

El neomunicipalismo en Bolivia no solo dio lugar a nuevos municipios, sino también a nuevas escalas de autoridades, nuevas competencias y prerrogativas, en el marco de una estrategia de descentralización que aspiraba a restringir responsabilidades al Estado central. Una de las figuras creadas fue el Distrito Municipal Indígena, DMI, aplicada principalmente en aquellos municipios de tamaño extenso, cuyo gobierno municipal no era indígena, y que contenía dentro de su jurisdicción a comunidades indígenas. Era una manera de reconocer, y dar obligaciones y derechos, a la población y autoridades de esos niveles de la organización político territorial del país. DMI se reconoce como una instancia de la Administración que hace posible a comunidades más pequeñas asumir funciones municipales; por lo que se «aplican las costumbres en la gestión local». 
No obstante, esa legislación sirvió para la gestión administrativa así como rápidamente fue asumida como autogobierno. LPP dotó a los distritos municipales de competencias; es la que se encarga de ejecutar los fondos públicos trasferidos desde el gobierno municipal, por lo que las autoridades tradicionales tienen aquí una participación significativa. De acuerdo con la Ley de Municipalidades: «Los distritos municipales son unidades administrativas integradas territorialmente dependientes del Gobierno Municipal, a partir de las cuales se deben elaborar planes de desarrollo humano sostenible» (artículo 163). Aun con el carácter vertical de la reforma, las figuras municipales fueron apropiadas con éxito en lugares en donde se había mantenido la organización ancestral de los ayllus, por ejemplo. Al paso de los años el distrito municipal indígena, en los lugares donde se formó, se fue configurando como una suerte de «municipio indígena», en la escala submunicipal, dando comienzo a una puja por la creación de nuevos municipios que solían esencializar sus discursos y etnizar su representación para legitimar su derecho al autogobierno, profundizando la diferencia. Este fue el caso del municipio de Jesús Machaca (Ticona y Albó 1997).

En este mismo orden, la legislación boliviana reconoció con el nombre de Organizaciones Territoriales de Base (OTBs) a las unidades submunicipales constituidas como sujetos de LPP, con personería jurídica, definidas como los sujetos de la Participación Popular en relación con los órganos públicos. Se reconoce como representantes de estas organizaciones a los hombres y mujeres, capitanes, jilacatas, curacas, mallcus - autoridades tradicionales - y secretarios generales de los sindicatos agrarios, según sus usos y costumbres. De acuerdo con la legislación, estos organismos participan en la ejecución de los fondos públicos y pueden ejercer facultades de control social.

LPP creó la figura de Comité de Vigilancia, CV, como un mecanismo de control social - y no así de fiscalización - en cada uno de los 314 municipios — antes llamados secciones de provincia-, rural y urbano. Fue concebido como un mecanismo que articula a OTBs con los gobiernos municipales. Las tareas de control social no son vistas solo como derechos, sino también como obligaciones. La Ley les daba la responsabilidad de vigilar la buena aplicación de los recursos municipales, y sus denuncias tenían carácter vinculante. Una denuncia bien documentada y verificada sobre malos manejos en el municipio podría tener como consecuencia suspender la asignación de recursos. 
Esas competencias y pregorrativas fortalecieron el músculo del autogobierno indígena, dando inicio a un proceso de revitalización, cuyas consecuencias empujaron hasta hacer posible el cambio autonómico que ahora se vive en Bolivia. María Eugenia Choque (2000) ha llamado la atención sobre los cambios que han ocurrido en este país desde los últimos quince años, en especial lo relativo al fortalecimiento del ayllu, al alertar estímulos en la participación local y el fortalecimiento de las autoridades locales. En su perspectiva uno de los aportes del municipalismo es haber visibilizado regiones y localidades tradicionalmente inexistentes para el Estado central y los gobiernos departamentales, y de gobiernos locales comunitarios e indígenas que habían pervivido al margen de las decisiones del Estado. Aunque la crítica de los años ochenta fue válida, toda vez que efectivamente LPP provocó una acentuada atomización de la territorialidad indígena; sin embargo tal proceso a la larga hizo posible la formación de «micro poderes barriales», logrando una reterritorialización del poder indígena (Mamani 2006).

Las trasformaciones en Bolivia movilizaron a la población en contra de las jerarquías criollas. Fortalecidos por el empoderamiento logrado desde abajo, los indígenas formaron cuadros que disputaron el poder en el ámbito regional y en las instituciones nacionales (Burguete 2007). Un movimiento social fortalecido modificó la organización del Estado al dar nacimiento a una nueva Constitución, que profundizó el autogobierno indígena local. Desde 2009 Bolivia se reconoce como un Estado plurinacional, ${ }^{8}$ estableciendo un régimen de autonomía multinivel. La conversión de distritos municipales indígenas a rango de municipio autónomo es una de las tareas que actualmente ocupa a los actores sociales indígenas de ese país. En Bolivia se viven actualmente procesos de municipalización del gobierno indígena —al dar nacimiento a los municipios autónomos-, y a la indianización del municipio, al ser reconocido el gobierno indígena como autoridad legal de los nuevos municipios del Estado plurinacional (Albo 2010).

Como ocurrió en Chile, en Bolivia el neoliberalismo exigió la reestructuración en la territorialidad del Estado, lo que trajo consecuencias diversas a los pueblos indígenas, con oportunidades y amenazas. Una vez más la institución municipal es un actor relevante. En Bolivia el nuevo municipio va más allá del municipio neoliberal, dando nacimiento a la figura 
del municipio autónomo y a la reindianización de sus instituciones. Como ocurre en otros países, la reindianización no supone la vuelta al pasado, sino la adecuación de esa institución a las realidades indígenas, así como a los ajustes que sufre el mismo Estado; toda vez que al final de cuentas, ahora como antes, el municipio forma parte de la organización estatal. Y mediante esta institución los pueblos indígenas suelen ser incorporados —o asimilados, según el caso- a la organización del Estado. Pero también, como Bolivia lo demuestra, es un espacio a través del cual los pueblos indígenas toman en sus manos el autogobierno local, obligando a la pluralización cultural del Estado. Los retos están de nuevo presentes.

\section{NEOMUNICIPALIZACIÓN EN VENEZUELA}

En Venezuela se produjeron procesos semejantes. En 1958, cuando cayó la dictadura de Marcos Pérez Jiménez (1952-1958), había 89 municipios, mientras que para el año 2004 su número se multiplicó hasta 336. Como en el resto de los países de América Latina, este proceso se produjo en la década de los ochenta y primeros años de los noventa. La Ley Orgánica de Régimen Municipal, LORM (1989), estableció el ayuntamiento como punto importante para la articulación entre el gobierno y sus ciudadanos, comunidades y grupos. El municipio se trasformó en portador y receptor de las ideologías de descentralización y reforma, tales como la reinvención del gobierno incorporando el principio de proximidad, la responsabilidad implícita y explícita de la visibilidad del gobierno, entre otros. La Ley preveía la creación de nuevos municipios al sumar un número de firmas ciudadanas que lo demandaran. Hubo tendencias de fragmentación de los grandes municipios, por lo que el área metropolitana de Caracas pasó de tres a seis municipios en el lapso de tres años (1989-1992).

En otro contexto, las políticas de descentralización, que incluye la reorganización político territorial y la creación de nuevos municipios en el territorio nacional, respondían a la otra cara de la moneda, que es la dimensión económica; en concreto, la expansión del capital trasnacional, el nuevo rol asignado a los Estados nacionales por la reforma del Estado, y más recientemente en esta nueva fase del capitalismo de reprimarización de la economía de América Latina. Para cumplir esos nuevos roles, el Estado se interesa por ampliar su presencia tanto institucional como regulatoria hacia nuevas regiones que antes no le eran prioritarias. Esto es particularmente relevante en zonas de interés para la inversión extranjera, como son las regiones selváticas repletas de biodiversidad, agua y, eventualmente, petróleo. 
Esto es particularmente visible en el proceso de reorganización político territorial realizado por el Estado venezolano. En una estrategia de la reforma del Estado, en 1988 se emitieron dos leyes: la Ley de Descentralización y la Ley de Municipios. Estas leyes reforzaron el sistema político nacional para que los gobernadores y alcaldes fueran elegidos por elecciones populares (Lauer 2005). En el año 1992, se llevaba a cabo en el país un proceso de reorganización territorial en el marco de Ley de Ordenamiento Político Territorial; en esa ocasión, el ahora estado Amazonas, situado al sur de Venezuela, fue constituido en el número veintidós del territorio federal. Al nacer como nueva entidad federativa se planeó desde el Congreso nacional la creación de siete nuevos municipios. Su demarcación inició en 1994. Antes, había un único municipio que era la capital en el Puerto de Ayacucho. Los siete nuevos municipios propuestos se expandían principalmente sobre regiones históricamente ocupadas por población indígena en la zona amazónica.

La historia de estos nuevos municipios hubiera sido semejante a las descritas para el caso boliviano arriba narrado; pero tres situaciones hicieron que adquiriera algunos matices: a) una fuerte lucha de los diecinueve pueblos indígenas de la amazonía venezolana que se opusieron a la demarcación municipal aprobada por el Congreso; b) la existencia previa de un articulado constitucional que establece que en Venezuela pueden funcionar y coexistir diferentes regímenes municipales — tipos de municipios-; c) y una exitosa estrategia jurídica de la Organización Regional de Pueblos Indígenas de Amazonas, ORPIA, ante la Corte Suprema de Justicia, que después de dos años reconoció el derecho de esos pueblos a participar en la división territorial de su entidad y anuló lo establecido en la Ley de División Político Territorial, con el argumento de que se realizó a espaldas de los interesados (Quispe 2005: 21). Sobre esa base se llevó a cabo una nueva propuesta de reorganización territorial, y se conformaron nuevos cuerpos de autoridad local. Una nota informativa resumió el desenlace de las controversias constitucionales de la siguiente manera:

La [nueva] propuesta establece la creación de siete nuevos municipios, uno más de los decididos en la ley anulada, y se acogió el pedido de uno especial para los yanomamis, uno de los pueblos más antiguos del mundo y que vive entre Brasil y Venezuela. También se determinó promover una forma de gobierno colectivo, donde el alcalde es sustituido por un coordinador, «que actuara como un servidor que propicie la actividad y defienda los derechos de la comunidad», precisó Guevara... «Queremos tener un 
gobierno de las comunidades, con circuitos indígenas y consejos interétnicos, donde todos los pueblos tendrán sus representantes y que sustituirán a los ediles tradicionales...», abundó... (Gutiérrez 1997: 2).

En febrero de 1995, ORPIA y sus aliados introdujeron en la Sala Plena de la entonces Corte Suprema de Justicia un recurso de nulidad, por inconstitucionalidad e ilegalidad, en contra de la Ley de División Político Territorial. En diciembre de 1996, casi dos años después, la Corte Suprema de Justicia dictó sentencia definitiva, la cual anulaba la ley promulgada y ordenaba la elaboración de una nueva ley que respetase los derechos de los pueblos indígenas. En noviembre de 1997, y tras la celebración del Primer Congreso Extraordinario de los Pueblos Indígenas en el que se legitimó el proceso de consulta en las comunidades indígenas, ORPIA entregó a la Asamblea Legislativa del estado de Amazonas un nuevo proyecto de ley.

En el alegato jurídico se denunció que la forma de municipalización que se había impuesto desde el Congreso nacional era de «municipios artificiales» que «separaban algunas etnias y forzaban a otras a convivir con rivales seculares», al tiempo que se violaban varios artículos de la Constitución nacional y la del propio Amazonas, que reconocen la existencia de la diversidad en los regímenes municipales en el país; así era legal que los amazónicos tenían derecho a decidir y a optar por un régimen municipal que les fuera culturalmente adecuado, proponiendo para ello la figura del «municipio ancestral». Entonces se definió que un municipio ancestral es aquel «respetuoso de los límites ambientales, la cosmovisión de cada pueblo, sus lugares sagrados y la gobernabilidad propia» (Gutiérrez 1997: 3).

Sin embargo, la Asamblea Legislativa insistió en que la propuesta de ORPIA era apartada de la legalidad. Finalmente, en diciembre de ese mismo año aprobó la Ley de Reforma Parcial de Ley de División Político Territorial sin volver a tomar en cuenta el proyecto alternativo elaborado por las organizaciones amazónicas. No obstante, ordenó a la Asamblea Legislativa del estado de Amazonas abstenerse de cualquier actuación tendiente a aprobar una Ley de División Político Territorial que no se adecuara a los términos señalados en el proyecto de los pueblos y comunidades indígenas. Pero tal decisión no modificó de fondo la propuesta gubernamental, sino que condujo únicamente a cambios menores, manteniéndose las jurisdicciones ya establecidas. En la mayoría de los casos, la población indígena dispersa en una amplia zona, en poblados pequeños, quedó subordinada a municipios con cabeceras en 
donde predomina la población no indígena; lo que ha impedido el autogobierno municipal indígena. Excepto el caso de los ke'kwana, en el Alto Orinoco (Lauer 2005).

Con esa decisión, el Estado venezolano ignoró las instituciones comunales de gobierno indígena, y tampoco aceptó sus formas de nombramiento y elección de autoridades, estableciendo los procedimientos electorales del sistema de partidos políticos. Ni siquiera reconoció la organización político territorial indígena tradicional de ocupación de la Selva, entre otros. El resultado fue la nulificación de la institucionalidad indígena previamente existente, siendo desplazada por la demarcación estatal (Quispe 2005).

Es importante mencionar que la Corte recibió la protesta de ORPIA porque la Ley Orgánica Municipal de 1989 establecía en sus artículos 26 y 27 el reconocimiento a la diversidad municipal, y preveía la posibilidad de que se pudieran establecer diferentes tipos de municipios, atendiendo a las condiciones de población, desarrollo económico, situación geográfica y otros factores de importancia. Dentro de la diversidad municipal se incluía aceptar la figura de «municipios con población indígena». Sin embargo, acotaba que independientemente del tipo de municipio todos ellos debían dejar a salvo los principios liberales, que establece que en todo caso será democrática y «responderá a la naturaleza propia del gobierno local» (Colmenares 2002: 201). Por este «candado» el reconocimiento de la diversidad no alcanzaba, sin embargo, ir más allá del perfil del municipio republicano, lo que en los hechos coartaba cualquier reconocimiento de la institucionalidad del gobierno local indígena.

Al final del proceso jurídico y político, los siete nuevos municipios fueron establecidos tal y como estaba legalmente previsto, y respondieron al perfil definido por la institución municipal nacional. En la opinión de Quispe (2005: 23), el problema principal residía en que el reconocimiento de un «municipio con población mayoritariamente indígena» no significaba la aceptación de la figura del «municipio indígena». En los hechos se trataba de la misma figura municipal, pero constituida encima de territorialidades que eran mayoritariamente indígenas, sin que tal elemento cuantitativo se tradujera en rasgos cualitativos. 
Así las cosas, presionado por las políticas de la reforma del Estado, el viejo municipio se reconfigura, por lo que es posible hablar de una «neomunicipalización» en los territorios indígenas, toda vez que es hijo de los tiempos del neoindigenismo, multiculturalismo, neoinstitucionalismo y neoliberalismo. Los casos de Chile, Bolivia y Venezuela nos ilustran que la reforma municipal, como parte de la reforma del Estado, es un espacio de disputa en donde se dirimen los derechos de los pueblos indígenas, y existe ahí una posibilidad nada despreciable para el autogobierno. Pero también se encuentran los riesgos para la fragmentación y la profundización de la intervención de la normatividad estatal, ansiosa por tomar decisiones en campos que tienen que ver con los recursos naturales y los territorios indígenas. El municipio es una institución útil para esta intervención.

\section{LA MUNICIPALIZACIÓN DEL GOBIERNO INDÍGENA EN TIEMPOS DEL ESTADO NEOLIBERAL: LOS RETOS}

Históricamente, el municipio ha sido una institución a la que el Estado — colonial, republicano nacional-popular, neoliberal o plurinacional - ha recurrido para instalar en los territorios indígenas su propia institucionalidad. Ya fuera como República de Indios, como municipio gaditano, como municipio libre o como municipio reformado - neomunicipalismo o municipio autónomo-, el municipio es una institución conocida por los pueblos indígenas. Institucionalidad que no es, regularmente, una calca exacta de lo que la norma estatal establece, sino que con cada nueva institución estatal establecida sobre territorio indígena, suele darse el inicio de una lucha desde los colectivos indígenas para intentar, otra vez, (re)significar, etnizar, las instituciones del Estado; y así convertir dicha institución «ajena» en «apropiada». Lucha histórica que nos ayuda a comprender la persistencia de los pueblos indígenas, siempre reinventados, hasta nuestros días (Burguete 2008).

Aunque el municipio ha sido una institución universal de gobierno local, en los hechos siempre es una configuración particular que da cuenta de las formas culturales de cómo se instala el Estado (García-Ruiz y García 2003); como resultado de las aperturas de campos de interlegalidad, en donde esos colectivos luchan por lograr que el municipio sea una institución culturalmente adecuada. Por ello mismo, como he intentado mostrar aquí, los pueblos indígenas de América Latina han realizado, en la larga duración, esfuerzos diversos y 
consistentes por lograr que el gobierno local legalmente reconocido sea pertinente con sus intereses.

En el paradigma del indigenismo asimilacionista que buscaba la integración de los indígenas a la nación, las «formas de gobierno indígena» se concebían como «remanentes» o residuos de instituciones propias del pasado indígena, que en un contínuum evolucionista deberían desaparecer una vez que quedaran incorporadas a la modernidad; es decir, a la institucionalidad del Estado moderno (Aguirre 1991). Pero, como la realidad se ha encargado de demostrarlo, la desaparición a la que habían sido condenados los gobiernos indígenas por las políticas integracionistas no se concretó plenamente; y hoy permanecen vigentes, insertos en una puja por su fortalecimiento creciente.

La clave de este cambio radica en que en nuestros días el Estado neoliberal con democracia electoral acepta que el gobierno local quede en manos de los ciudadanos de las entidades locales, sin que la identidad étnica sea una objeción. El incorporar al discurso del Estado el recurso de la diferencia cultural, que significa un matiz importante en la estrategia del Estado nación para la homogenización cultural y política — sin que suponga la renuncia a su hegemonía-, coloca a los gobiernos locales indígenas en otra coyuntura. Los cruces que se producen entre democracia local y diversidad cultural, ambos principios caros al Estado neoliberal, han hecho posible la emergencia de gobiernos locales que se asumen como «gobiernos indígenas», que gozan de la legitimidad que les da el haber ascendido al poder mediante un procedimiento electoral democrático.

Tal cosa es un tenso equilibrio. Con el reconocimiento de la diversidad, el Estado busca y encuentra nuevos mecanismos para rearticular su hegemonía, y trata de penetrar los intersticios autonómicos, como sucede hoy día con los gobiernos locales indígenas, incorporándolos a la lógica estatal mediante los procedimientos democrático electorales. Así se produce una interrelación tensa. Por un lado favorece la ampliación del Estado y su intervención dentro de los espacios étnicos indígenas, al mismo tiempo que se produce el reconociendo de derechos indígenas, y la configuración de una suerte de autogobierno indígena que puja por el reconocimiento expreso de la diversidad. 
Como arena de significación, el municipio es también motivo de disputa dentro de los mismos actores indígenas; en un campo de posicionamientos político ideológico. Algunos de esos actores cuestionan sobre si el gobierno municipal debe ser entendido como sinónimo de «gobierno indígena», en el ejercicio del derecho a la autodeterminación y autonomía. Incluso, se interrogan sobre si es legítimo que indígenas que han ascendido al gobierno local mediante procedimientos electorales pueden «representar» a la comunidad de miembros. O aún cuestionan sobre si en municipios pluriétnicos —indígenas-mestizos - las autoridades municipales indígenas pueden asumirse como «gobierno indígena», toda vez que en su gestión incorporan perspectivas de interculturalidad y no como gobierno comunal.

Todos estos, y más, son los retos que enfrenta el gobierno indígena en tiempos de multiculturalismo. En la medida en que los indígenas asumen el reto de disputar el poder local en municipios pluriétnicos, tienen el reto de gobernar a una población de composición étnicamente diversa. Es decir, deben gobernar dando respuesta al Otro étnico. Esto es visto como oportunidad para la innovación política, como construir estrategias para ambos grupos étnicos, combinando discursos, prácticas, recursos e instituciones propias de un «gobierno indígena», con otros que respondan a los reclamos de ciudadanía y sean aceptados como adecuados por la población no indígena que vive en la jurisdicción. Por ejemplo, estos son los desafíos que asumieron los gobiernos de la prefectura de la provincia de Cotopaxi y del municipio de Saquisilí de Ecuador, que gobiernan en contextos pluriétnicos (Tibán y García 2008), y de la comuna de Tirúa en Chile (Mariman y Alwin 2008). En esos escenarios, uno de los principales retos del gobierno indígena fue demostrar que podían ser «un buen gobierno»y, aún más, un «mejor gobierno». Por esta presión, introdujeron innovaciones en el diseño institucional y construyeron nuevas formas de gobierno que incluyeron la reinvención de instituciones indígenas, como la asamblea, las reuniones amplias, los consensos y los acuerdos; mismas que quedaron incorporadas como prácticas en el ejercicio del gobierno local, aunque resignificadas (Burguete 2008).

Pero, en otros casos, el «gobierno indígena» en el municipio también es cuestionado. Algunos autores mencionan que los indígenas gobernantes en municipios no siempre se diferencian del resto de sus pares no indígenas. Durston (2007) observa que la «subcultura» política del 
clientelismo es frecuente en las relaciones que establecen las autoridades locales con sus representados en regiones indígenas de Chile, y no se logran distinguir diferencias significativas entre los políticos indígenas y quienes no lo son. De tal manera que los indígenas hacen política incorporándose a grupos políticos, en donde las lealtades étnicas no son siempre el factor que las articula, en donde relaciones de prebendalismo son criterios para la adhesión política.

Esta perspectiva es compartida por Norero (2007) al estudiar el gobierno mapuche de BioBio, pues observa que la nueva participación de los indígenas en la disputa política con reglas electorales ha tenido claroscuros. La autora afirma que no advierte diferencias significativas en la gestión de ese gobierno municipal. Lo que conduce a interrogarse sobre si acaso la etnicidad no es únicamente un recurso que usan algunos liderazgos indígenas en el ascenso al poder, sin implicaciones significativas para los colectivos indígenas.

Esta pregunta suelen hacerla diversos actores del movimiento indígena que no se sienten satisfechos con la neomunicipalización, ni por ser el municipio el espacio que el Estado ofrece como único lugar para el autogobierno indígena. Por el contrario, lo advierten como un peligro, toda vez que las instituciones (neo)municipales suelen desplazar la institucionalidad que es percibida como propia.

Tampoco dan cuenta de cambios sustanciales en la presunta nueva relación entre el Estado y los pueblos indígenas, que se supone debía de resultar después de las reformas constitucionales que dieron lugar a las políticas de reconocimiento. Desafortunadamente, el multiculturalismo como política de Estado no tuvo como propósito básico empoderar a los pueblos indígenas, sino favorecer a las instituciones del Estado, para la reconstrucción de su hegemonía, fuertemente cuestionada por las luchas indígenas que rechazaron las políticas asimilacionaistas. Frente al neomunicipalismo como respuesta limitada, una respuesta autonómica desde las organizaciones indígenas, ha estado el «giro hacia adentro», de retrotraimiento, que intenta romper todo contacto con el Estado, maximizando la diferencia, para marcar de forma radical las fronteras étnicas y definir de esta manera su propio camino, alentando procesos de microetnicidad y microgobierno, rechazando la figura municipal. 
El retrotraimiento es también la estrategia que ha usado el movimiento maya de Guatemala, que ha sacralizado la política para distanciarse de los partidos y otros actores convencionales (Bastos, Hernández y Méndez 2008). Es la misma estrategia que han usado algunos pueblos de las zonas bajas amazónicas en países como Colombia, Ecuador y Bolivia. En este mismo orden se inscriben las acciones de estos pueblos indígenas de las zonas amazónicas, que han decidido declararse en «aislamiento voluntario» para alejarse de la relación con el Estado, sus instituciones y sus proyectos modernizadores. Todas estas iniciativas, al declarar su intención de romper su contacto con el Estado y con el «mundo occidental», implícita y explícitamente rechazan el proyecto de vida que ofrece occidente - incluyendo la figura municipal—, y demandan el derecho a pensar el mundo desde múltiples perspectivas civilizatorias (Parellada 2006).

Esa estrategia es, al mismo tiempo, la forma de rechazar la presencia de las petroleras, mineras y empresas forestales que penetran en sus territorios, gracias a las concesiones dadas por los Estados. El entorno global contribuye a alentar las tendencias del «giro hacia adentro». Siendo la globalización un fenómeno promovido por el capitalismo, éste se manifiesta, entre otros modos, en la expansión de la economía de libre mercado y en la apertura de fronteras, que llegan hoy día hasta las regiones más recónditas. Frente al poder de los grandes capitales — petroleras, mineras, empresas forestales, de ecoturismo, de privatización del agua—, al despliegue de los acuerdos comerciales y a un escenario de renuncia del Estado por la defensa de la soberanía nacional, agudizado por la creciente importancia que adquieren las materias primas en el subcontinente latinoamericano; los pueblos indígenas se sienten amenazados y recurren al reclamo de su propia soberanía, mediante la autonomía, y de su cosmovisión para retrotraerse. Con ello buscan asumir la defensa de sus recursos estratégicos, sus saberes y conocimientos, disputando al Estado y al capital su control para convertirlos en intersticios autonómicos.

Para ratificar esa voluntad, los pueblos indígenas proceden a la primordialización o esencialización de prácticas y discursos, con los que tratan de dar nuevos sentidos a la diferencia y mostrarse como un proyecto alternativo a la crisis que vive el modelo capitalista y la sociedad occidental, creando nuevos conceptos como el de Buen Vivir (Choquehuanca 2010). Principios incorporados a la nueva Constitución de Ecuador y Bolivia. Investirse de 
inconmensurabilidad para distanciarse radicalmente de occidente, y con ello del Estado $-\mathrm{y}$ sus instituciones, incluyendo el municipio-y el capitalismo neoliberal; es una estrategia política a la que con mayor frecuencia los pueblos indígenas recurren para reforzar su propia institucionalidad. Apelar a la cosmovisión, la espiritualidad, la filosofía comunal, al cosmos, al ser, a la sabiduría de los antepasados y la armonía con la naturaleza y con la madre tierra, son estrategias, prácticas y discursos que se representan como saberes de las comunidades, pueblos, organizaciones y actores indígenas para construir sobre su base la legitimidad de su retrotraimiento.

Esas nociones son (re)elaboradas por sus liderazgos para posicionarse políticamente, desafiar el estado de cosas existente y rechazar luego el actual modelo capitalista calificado de depredador, con vistas a formular su propia alternativa, misma que interpela a occidente, al Estado y al capital. Estos planteamientos, que en algún momento consideramos como «etnicistas», «esencialistas», «milenaristas», «culturalistas», «pasatistas» y hasta «ingenuos» o «románticos», parecen adquirir hoy día nuevos sentidos y filo trasformador. En esta nueva significación los discursos de resistencia indígena buscan movilizar a los actores en la elaboración de prácticas y discursos para construir una suerte de «coraza» que impermeabilice sus territorios, jurisdicciones e instituciones, y ejercer de esta forma un mayor control, a partir de la creación de nuevos intersticios autonómicos.

Negarse a aceptar la institucionalidad del Estado fue la estrategia que también desplegó el Ejército Zapatista de Liberación Nacional, EZLN, cuando el gobierno federal les ofreció reconocer sus municipios autónomos de facto, bajo la figura de la «remunicipalización». Aunque los zapatistas rechazaron las políticas gubernamentales para dar nacimiento a nuevos municipios en su área de influencia, la demanda de creación de nuevos municipios en el estado —entre 1998 y 1999 - llegó casi a un centenar (Leyva y Burguete 2007, Burguete 2009). Importa recordar que la formación de nuevos municipios y la remunicipalización fueron una de las demandas más consistentes que movilizó diversas luchas indígenas $-\mathrm{y}$ de mestizos indianizados - a la largo del territorio nacional, y demanda constante dentro de las luchas indígenas autonómicas en México, en el último lustro del siglo XX (Martínez 2007). 


\section{A MANERA DE REFLEXIÓN FINAL}

El municipio es en la actualidad una arena en donde se disputa el gobierno indígena y la autonomía. Su apropiación contiene una contradicción; por un lado contiene un propósito integracionista y asimilacionista, por el otro es también oportunidad. Los pueblos, comunidades y organizaciones indígenas, dentro de los movimientos indígenas, debaten entre sí, a veces de manera ríspida y confrontada, sus posicionamientos frente al Estado y al nuevo municipio reformado: si se acepta o se rechaza. No hay respuestas únicas, y todos los días se práctica el juego político de la aceptación, pero luego apropiación, para proceder a su «indianización». El camino es, sin embargo, riesgoso. Es una operación política largamente aprendida durante más de quinientos años, en donde se gana y se pierde. Lo importante es que al mismo tiempo contiene la oportunidad de la resistencia. Las amenazas de la neomunicipalización son ciertas y los peligros del despojo territorial inminentes; sin embargo, es una realidad difícil de evadir, aunque sí es posible resistir.

En tiempos de multiculturalismo, los pueblos indígenas pujan por significar culturalmente la democracia y las instituciones del Estado, lo que plantea desafíos. Regularmente los actores indígenas se posicionan frente a este dilema de dos maneras: o lo abandonan como espacio de lucha y dejan abierto el camino para que este opere mediante las prácticas propias del multiculturalismo en su diseño neoliberal puro y duro. O lo toman como un campo de disputa y asumen el reto de intentar (re)significarlo, y con ello abrir la oportunidad e impulsar desde allí procesos de construcción de instituciones propias, en un proceso de apropiación.

En este marco general de globalización neoliberalismo y multiculturalismo, el gobierno indígena se reconfigura, vuelve a mutar, como antes lo había hecho en sus distintas formas de constitución municipal y de relación con el Estado, ya fuera colonial, republicano, nacional popular o neoliberal. Como he intentado demostrar en esta colaboración, el municipio es un riesgo pero también una oportunidad. Lo deseable es lograr un tipo de municipio culturalmente adecuado a cada realidad sociocultural; lo que haría posible lograrlo, instituyendo regímenes con un enfoque multimunicipal. 
En otro lugar he planteado, para el caso de México, una reforma constitucional al artículo 115 de su Constitución que modifique el «municipio libre»-como institución municipal nacional, universal para todos los municipios de México- o se instituya un «régimen multimunicipal» que reconozca la diversidad municipal, donde se inserte la figura de «municipio indígena», que pueda ser llevado a cabo de manera diferenciada en cada contexto local (Burguete 2008a). Lograr el reconocimiento de la diversidad municipal es una ruta posible para el reconocimiento de la institucionalidad municipal, y con ello el ejercicio del derecho al autogobierno indígena, en el horizonte del derecho de la autodeterminación de los pueblos. 


\section{BIBLIOGRAFÍA}

Aguirre Beltrán, Gonzalo, 1952, «El gobierno indígena en México y el proceso de aculturación», América Indígena, v. XII, n. 4, octubre, Instituto Indigenista Interamericano, México, pp. 271-297.

1991, Formas de gobierno indígena. Obra Antropológica IV, Universidad Veracruzana/INI/ Gobierno del estado de Veracruz, Tercera edición de FCE, México.

Albó, Xavier, 2002, Pueblos indios en la política, CIPCA/Plural Ediciones, Bolivia.

Albó, Xavier, 2010, «Las flamantes autonomías indígenas en Bolivia», en La autonomía a debate. Autogobierno indígena y Estado plurinacional en América Latina, coordinado or Miguel González, Araceli Burguete y Pablo Ortiz-T., FLACSO, Ecuador (en prensa).

Andara M., Abraham Enrique, 2007, «La segunda generación de la Reforma del Estado y su efecto en la administración pública local de América Latina», Provincia, n. 17, enero-junio, Universidad de los Andes, Venezuela, pp. 77-105.

Assies, Willem, 2003, «La descentralización a la boliviana y la "economía política" del reformismo», en Gobiernos locales y reforma del Estado en América Latina. Innovando la gestión pública, editado por Willem Assies, COLMICH, Zamora, Michoacán, pp. 135-160.

Assies, Willem, 2003a, «La descentralización en perspectiva», en Gobiernos locales y reforma del Estado en América Latina. Innovando la gestión pública, editado por Willem Assies, COLMICH, Zamora, Michoacán, pp. 13-35.

Bastos, Santiago, Domingo Hernández Ixcoy y Leopoldo Méndez, 2008, «Reconocimiento, reconstitución del pueblo maya en Guatemala: entre la acción autónoma y el reconocimiento estatal», en Gobernar (en) la diversidad: experiencias indígenas desde América Latina. Hacia la investigación de co-labor, coordinado por Xochitl Leyva, Araceli Burguete y Shannon Spedd, CIESAS/FLACSO Ecuador/FLACSO Guatemala, México, pp. 305-342. 
Beaucage, Pierre, 1988, «La condición indígena en México», Revista Mexicana de Sociología 50, n. 1, IIS-UNAM, México, pp. 191-211.

Bengoa, José, 2000, La emergencia indígena en América Latina, FCE, Chile.

Bonfil Batalla, Guillermo, 1972, «El concepto de indio en América: una categoría de la situación colonial», Anales de Antropología, v. IX, IIA-UNAM, México, pp. 105-124.

1988, «La teoría del control cultural en el estudio de procesos étnicos», Anuario Antropológico, n. 86, Universidad de Brasilia, Brasil, pp. 13-53.

Burgos Guevara, Hugo, 1995, El Guamán, el Puma y el Amaru. Formación estructural del gobierno indígena en Ecuador, Biblioteca Abya Yala, Ecuador.

Burguete Cal y Mayor, Araceli, 2007, «De la resistencia al poder. Articulación y repertorios indígenas en la lucha por el poder político: el ensayo boliviano», Revista Argumentos, v. 20, n.55, septiembre-diciembre, UAM-X, México, pp. 51-73.

2008, «Gobernar en la diversidad en tiempos de multiculturalismo en América Latina», en Gobernar (en) la diversidad: experiencias indígenas desde América Latina. Hacia la investigación de co-labor, coordinado por Xochitl Leyva, Araceli Burguete y Shannon Spedd, CIESAS/FLACSO Ecuador/FLACSO Guatemala, México, pp. 15-64.

2008a, «Municipios indígenas: por un régimen multimunicipal en México», Alteridades, v. 18, n. 35, enero-junio, UAM-I, México, pp. 67-83.

Carmagnani, Marcello, 1988, El regreso de los dioses. El proceso de reconstitución de la identidad étnica en Oaxaca. Siglos XVII y XVIII, FCE, México.

Cavarozzi, Marcelo 1991, «Más allá de las transiciones a la democracia en América Latina», Revista de Estudios Políticos (Nueva Época), n. 74, octubre-diciembre, Centro de Estudios Constitucionales, Madrid, pp. 85-111. 
Colmenares Olivar, Ricardo, 2002, «El derecho a la autonomía de los pueblos indígenas en Venezuela», Revista CENIPEC, n. 21, enero-diciembre, Venezuela, pp. 185-217.

Clavero, Bartolomé, 2002, «Multiculturalismo constitucional, con perdón, de veras y en frío», Revista Internacional de los Estudios Vascos, v. 47, n. 1, pp. 35-62.

Chávez Orozco, Luis, 1943, Las instituciones democráticas de los indígenas mexicanos en la época colonial, Ediciones del Instituto Indigenista Interamericano, México.

Chevalier, Francois, 1989, «La libertad municipal, antigua y permanente reivindicación mexicana», Revista Mexicana de Sociología, a. LI, n. 2, abril-junio, IIS-UNAM, México, pp. 433-444.

Chiaramonti, Gabriella, 2007, "De marchas y contramarchas: apuntes sobre la institución municipal en el Perú (1812-1861)", en Araucaria. Revista Iberoamericana de Filosofía, Política y Humanidades, Año 9, Núm. 18, Sevilla, Universidad de Sevilla, pp. 150-179.

Choque, María Eugenia, 2000, «La reconstitución del ayllu y los derechos de los pueblos indígenas», Las sociedades interculturales: un desafío para el siglo XXI, coordinado por Fernando García, FLACSO, Ecuador, pp. 13-30.

De Gortari Rabiela, Hira, 1997, «Ayuntamientos y ciudadanos. La ciudad de México y los estados: 1812-1827», Tiempos de América. Revista de Historia, Cultura y Territorio, n. 1, Universitat Jaume I., Castellón, pp. 113-130.

Díaz-Polanco, Héctor, 1996, Autonomía regional: la autodeterminación de los pueblos indios, Siglo XXI, México. 
Díaz-Polanco, Héctor y Araceli Burguete, 1996, «Sociedad colonial y rebelión indígena en el obispado de Oaxaca (1660)», en El fuego de la inobediencia. Autonomía y rebelión india en el Obispado de Oaxaca, coordinado por Héctor Díaz-Polanco, CIESAS, México, pp. 17-52.

Durston, John, 2007, «Poder local y movimiento étnico en Villarica, Chile», en Movimientos indígenas y gobiernos locales en América Latina, México, Chile, editado por Willem Assies y Hans Gundermann, Colmich/Universidad Católica del Norte de Chile, pp. 290-328.

Escobar Ohmstede, Antonio, 1996, «Del gobierno indígena al Ayuntamiento constitucional en las Huastecas hidalguense y veracruzana, 1780-1853», Mexican Studies/Estudios Mexicanos, v. 12, n. 1, Universidad de California, EUA, pp. 1-26.

Espinoza Soriano, Waldemar, 2007, «Reacción de los indígenas de Cajamarca frente a la Independencia de Trujillo y Lima, 1821-1822», Investigaciones Sociales, n. 18, Universidad Nacional Mayor de San Marcos, Lima, pp. 197-220.

Foerster, Rolf, 2007, «El horizonte del municipio en la dirigencia de las comunidades mapuche del Valle de Cayupil, Chile», en Movimientos indígenas y gobiernos locales en América Latina, editado por Willem Assies y Hans Gunderman, Colmich/IWGIA/ Universidad Católica del Norte de Chile, San Pedro Atacama, Chile, pp. 328-355.

García-Ruiz, Jesús y Federico García, 2003, «Por una etnología del Estado», Revista El Cadejo, n. 9, Instituto Centroamericano de Prospectiva e Investigación, Guatemala, pp. 5-16.

Gundermann K., Hans, 2004, «Sociedades indígenas, municipio y etnicidad: La transformación de los espacios políticos locales andinos en Chile», en Los desafíos de la interculturalidad: identidad, política y derecho, editado por Milka Castro-Lucic, Universidad de Chile, Santiago de Chile, Chile, pp. 291-328.

Gundermann K., Hans, 2007, «Municipios y pueblos indígenas en Chile», en Movimientos indígenas y gobiernos locales en América Latina, editado por Willem Assies y Hans 
Gundermann, Colmich/IWGIA/Universidad Católica del Norte de Chile, San Pedro Atacama, Chile, pp. 161-198.

Gros, Christian, 2000, Politicas de la etnicidad: identidad, estado y modernidad, Instituto Colombiano de Antropología, Bogotá, Colombia.

Koersbaek, Leif, (ed.), 1996, Introducción al sistema de cargos. Antología, Universidad Autónoma del Estado de México, Toluca, México.

Lalander, Rickard, 2005, «Movimiento indígena, participación política y buen gobierno municipal en Ecuador: el alcalde Mario Conejo de Otavalo», Ecuador Debate, n. 66, CAAP, Quito, Ecuador pp. 153-181.

Lauer, Mattew, 2005, «Líderes políticos indígenas en Amazonía: política y autorepresentación entre los ye'kwana del Alto Orinoco», AIBR. Revisa de Antropología Iberoamericana, mayo-junio, n. 041, Antropólogos Iberoamericanos en Red, Madrid, pp. 120.

León Trujillo, Jorge, 1994, De campesinos a ciudadanos diferentes: el levantamiento indígena, CEDIME-Abya Yala, Quito.

Leyva, Xochitl y Araceli Burguete, 2007, La remunicipalización en Chiapas. Lo político y la política en tiempos de contrainsurgencia, CIESAS, México.

Lockhart, James, 1999, Los nahuas después de la Conquista. Historia social y cultural de la población indígena del México central, siglos XVI-XVIII, FCE, México.

Mamani Ramírez, Pablo, 2006, «Dominación étnica, de clase y territorialización del poder indígena en Bolivia», en Movimiento indígena en América Latina: resistencia y proyecto alternativo, v. II, coordinado por Raquel Gutiérrez y Fabiola Escárzaga, Casa Juan Pablos y coeditores, México, pp. 35-53. 
Mardones Z., Rodrigo, 2006, «Descentralización y transición en Chile», Revista de Ciencia Política, v. 26, n. 1, Pontificia Universidad Católica de Chile, Instituto de Ciencia Política, Santiago de Chile, pp. 3-24.

Martínez Barragán, Hirineo (coord.), 2007, Creación de nuevos municipios en México: procesos y perspectivas, Universidad de Guadalajara, México.

Marimán, Pablo y José Alwin, 2008, «Las identidades territoriales mapuche y el Estado chileno: conflicto interétnico en un contexto de globalización», en Gobernar (en) la diversidad: experiencias indígenas desde América Latina. Hacia la investigación de co-labor, coordinado por Xochitl Leyva, Araceli Burguete y Shannon Spedd, CIESAS/FLACSO Ecuador/FLACSO Guatemala, México, pp. 111-150.

Menegus Bornemann, Margarita, 1996, «Comunidad, pueblo o corporación: los indios de la Nueva España en el siglo XVIII. Una revisión historiográfica», en Historia y Universidad. Homenaje a Lorenzo Mario Luna, coordinado por Enrique González González, UNAM, México, pp. 51-62.

Murra, John, 1983, La organización económica del Estado Inca, Siglo XXI/IEP, México.

Nickson, Andrew, 2003, «La transferencia de políticas y reforma de la administración del sector público en América Latina: el ejemplo de la Nueva Gestión Pública», en Gobiernos locales y reforma del Estado en América Latina, editado por Willem Assies, Colmich, México, pp. 35-62.

Norero, María Rosa, 2007, «Municipio y etnicidad. El caso de la comuna del Alto BioBio», tesis de licenciatura, Universidad Academia de Humanismo Cristiano, Santiago de Chile.

Ortiz Escamilla, Juan y José Antonio Serrano Ortega (eds.), 2007, Ayuntamientos y liberalismo gaditano en México, Colmich, Zamora, Michoacán. 
Palomo, Dolores, 2009, «Los Ayuntamientos de los pueblos indígenas en Chiapas en el siglo XIX y su relación con los asuntos de justicia», Anuario de Estudios Americanos, n. 66, enero junio, Sevilla, pp. 21-46.

Parellada, Alejandro, 2006, Pueblos indígenas en aislamiento voluntario y contacto inicial en la Amazonía y el Gran Chaco, IWIA, Lima, Perú.

Pastor, Rodolfo, 1987, Campesinos y reformas: La mixteca, 1700-1856, COLMEX, México.

Prokosch, Eric, 1973, «Gobiernos indios "tradicionales" en los Altos de Chiapas», en Estudios de Cultura Maya, v. IX, UNAM-Centro de Estudios Mayas, México, pp. 151-160.

Quispe, María Teresa, 2005, Venezuela. Gobiernos locales y pueblos indígenas, ORPIA/ IWGIA, Venezuela.

Robles Mendoza, Román, 2002, Legislación peruana sobre comunidades campesinas, Universidad Mayor de San Marcos-Facultad de Ciencias Sociales, Lima, Perú.

Rus, Jan, 2004, «La comunidad revolucionaria institucional: la subversión del gobierno indígena en Los Altos de Chiapas. 1936-1976», en Chiapas. Los rumbos de otra historia, coordinado por Juan Pedro Viqueira y Mario Humberto Ruz, tercera reimpresión, UNAM/CIESAS, México, pp. 251-278.

Sala Vila, Nuria, 1992, «La Constitución de Cádiz y su impacto en el gobierno de las comunidades indígenas en el Virreinato del Perú», Boletín Americanista, n. 42-43, Barcelona, pp. 51-70.

Sánchez, Consuelo, 1999, Del indigenismo a la autonomía, Siglo XXI, México.

Santos, Boaventura de Sousa, 2003, Crítica de la razón indolente. Contra el desperdicio de la experiencia. Vol. I. Para un nuevo sentido común: la ciencia, el derecho y la política en la transición paradigmática, Ed. Desclée de Brower, Bilbao. 
Tax, Sol, [1937] 1996, «Los municipios del altiplano mesooccidental de Guatemala», en Introducción al sistema de cargos, antologado por Leif Korsbaek, Universidad Autónoma del Estado de México, Toluca, México, pp. 87-112.

Tibán, Lourdes y Fernando García, 2008, «De la oposición y el enfrentamiento al diálogo y las alianzas: la experiencia de la CONAIE y el MICC en Ecuador», en Gobernar (en) la diversidad: experiencias indígenas desde América Latina. Hacia la investigación de co-labor, coordinado por Xochitl Leyva, Araceli Burguete y Shannon Spedd, CIESAS/FLACSO Ecuador/FLACSO Guatemala, México, pp. 271-304.

Ticona Alejo, Esteban y Xavier Albó, 1997, La Lucha por el Poder Comunal, v. 3, Serie Jesús de Machaqa: la Marka Rebelde, CEDOIN/CINCA, Bolivia.

Velásquez Cepeda, 2000, Cristina, El nombramiento. Las elecciones por usos y costumbres en Oaxaca, Instituto Electoral de Oaxaca, México. 


\section{DOCUMENTOS EN VERSIÓN DIGITAL}

Albó, Xavier y Carlos Romero, 2009, «Autonomías indígenas en la realidad boliviana y su nueva constitución», en http://www.vicepresidencia.gob.bo/Portals/0/documentos/ AUTONOMIAS_INDIGENAS1.pdf [consulta: agosto de 2009].

Burguete Cal y Mayor, Araceli, 2009, «El municipio en Chiapas en la coyuntura zapatista: un actor inesperado», Revista Encrucijada Americana, a. 3, n. 1, Universidad Alberto Hurtado, Chile, en http://www.encrucijadaamericana.cl/articulos/otonoinvierno2009/7-FormatoBurguete-municipio-ok.pdf [consulta: abril de 2010].

Constitución de la República de Bolivia. Constitución de 1967 con reformas introducidas por Ley $\mathrm{N}^{\mathrm{o}} 1585$ del 12 de agosto de 1994, en http://pdba.georgetown.edu/Constitutions/ Bolivia/1967bolivia1994.html [consulta: agosto de 2009].

Constitución de la República del Ecuador, Asamblea Constituyente, en http://www.asambleaconstituyente.gov.ec/documentos/constitucion_de_bolsillo.pdf [consulta: agosto de 2009].

Constitución Política del Estado. República de Bolivia, en http://www.vicepresidencia.gob.bo/Portals/0/documentos/NUEVA_CONSTITUCION_POLI TICA_DEL_ESTADO.pdf [consulta: agosto de 2009].

Convenio OIT Núm. 169 sobre Pueblos Indígenas y Tribales en Países Independientes, 1989, en http://www.ilo.org/public/spanish/region/ampro/lima/publ/conv-169/convenio.shtml [consulta: julio de 2009].

Choquehuanca, David, 2010, «25 postulados para entender el "vivir bien o buen vivir”», en http://www.economiasolidaria.org/taxonomy/term/924/all [consulta: julio de 2010]. 
González Casanova, Pablo, s/f, «Colonialismo interno [una redefinición]», http://bibliotecavirtual.clacso.org.ar/ar/libros/campus/marxis/P4C2Casanova.pdf [consulta: julio de 2009].

González Madrid, Miguel, s/f, «Tlaxcala: las elecciones municipales extraordinarias y el futuro inmediato del neomunicipalismo», en http://www.bibliojuridica.org/libros/ 4/1834/17.pdf [consulta: julio de 2010].

Gutiérrez, Estrella, 1997, «Proponen nueva división territorial diecinueve pueblos indígenas derrotaron la imposición de municipios en Amazonas», Revista Rebelión, 17 de marzo, en http://www.eurosur.org/rebelion/hemeroteca/ecologia/indig003.htm [consulta: marzo de 2005].

Ley de Municipalidades de Bolivia, 1999, en http://www.derechoteca.com/gacetabolivia/ley2028-del-28-octubre-1999.htm [consulta: agosto de 2009].

Ley de Participación Popular, en http://www.legislacionmunicipal.fam.bo/Archivo/ Docs/Leyes/Ley_1551.pdf [consulta: agosto de 2009].

Ley Orgánica de Régimen Municipal, en

http://www.gobiernoenlinea.ve/legislacion-view/sharedfiles/LeyOrganicaRegimenMunicipal. pdf [consulta: agosto de 2009].

Martínez Cobo, Miguel Alfonso, 1999, «Los derechos humanos de las poblaciones indígenas. Estudio sobre los tratados, convenios y otros acuerdos constructivos entre los Estados y las poblaciones indígenas. Informe final», en http://www.unhchr.ch/Huridocda/ Huridoca.nsf/0/b5f7c60307b79f9d802567c4004ba1e6?Opendocument [consulta: julio de 2009].

Organización de las Naciones Unidas, 2007, «Declaración de las Naciones Unidas sobre los derechos de los pueblos indígenas. Resolución aprobada por la Asamblea General, 13 de 
septiembre de 2007», en http://www.un.org/esa/socdev/unpfii/es/drip.html [consulta: julio de 2009].

Schkolnik, Susana y Fabiana del Popolo, 2005, «Los censos y los pueblos indígenas en América Latina: una metodología regional», Revista Notas de Población, n. 79, CEPAL/CELADE, CELADE, en http://www.eclac.cl/publicaciones/xml/5/23525/notas79cap4.pdf [consulta: julio de 2009].

Sierra, María Teresa, 2005, «Derecho indígena y acceso a la justicia en México. Perspectivas desde la interlegalidad», en http://www.iidh.ed.cr/BibliotecaWeb/Varios/Documentos/ BD_2061358847/Docs\%20Revista\%2041/1689-Sierra\%20Maria\%20Teresa.pdf [consulta: julio de 2009].

Stavenhagen, Rodolfo, 1991, «Los conflictos étnicos y sus repercusiones en la sociedad internacional», Revista Internacional de Ciencias Sociales, n. 157, UNESCO, en http://www.cholonautas.edu.pe/modulo/upload/CONFLICTOS\%20ETNICOS.pdf [consulta: julio de 2009].

Valladares, Laura, 2009, «La construcción de democracias indígenas desde abajo. Los caminos de la colonización del Estado en tiempos multiculturales», en http://lasa.international.pitt.edu/members/congress-papers/lasa2009/files/ValladaresLaura.pdf. [consulta: abril de 2010]. 
Notas

\footnotetext{
${ }^{1}$ Esta es una versión parcialmente modificada del texto publicado como: Burguete Cal y Mayor, A. (2009). «La municipalisation de la gouvernance locale autochtone en Amérique latine», Télescope, v. 15, n. 3, Quebec, Canada, pp. 31-52. La autora agradece a los/las dictaminadores anónimos, quienes con sus acertadas sugerencias contribuyeron a mejorar el documento.

${ }^{2}$ Laura Valladares llama a los cambios que se realizan en el Estado, que resulta de la acción política indígena para que ése se constituya como multicultural, como «colonización del Estado» desde abajo (Valladares 2009).

${ }^{3}$ Guillermo Bonfil ha llamado a esta estrategia indígena como «control cultural», en donde «lo ajeno» puede ser culturalmente apropiado, mediante el proceso de control cultural (Bonfil 1988).

${ }^{4}$ Estos son los fundamentos del reconocimiento de los derechos de los pueblos indígenas por la Organización de las Naciones Unidas (ONU) en 2007.

${ }^{5} \mathrm{Al}$ estudiar la formación de los gobiernos indígenas en la zona andina, Burgos (1995: 321) elabora un cuadro jerárquico de «equivalencia prehispánica del Cabildo de Indios en los Andes», en donde los cargos de gobierno, propios de la estructura inca, fueron reelaborados para ocupar los nuevos cargos coloniales. Algunos de esos cargos: Guaranga (cacique principal); Pisca-pachaca (mandón mayor); Pachaca camachicoc (alcalde ordinario); Pisca-changa camachicoc (Regidor); Chunga camachicoc (alguacil); Pisca camachicoc (fiscales).

${ }^{6}$ Las personas nativas de Cádiz, España, son llamados «gaditanos». De allí con frecuencia la Constitución, y el ayuntamiento que surge de dicha Constitución, son llamados «Constitución gaditana», «Carta gaditana», o «ayuntamientos gaditanos» (Ortiz y Serrano 2007).

${ }^{7}$ Ley de Participación Popular. Disponible en http://www.fndr.gov.bo/doc_normas/ley1551.pdf. Consultado en agosto de 2009.

${ }^{8}$ La nueva «Constitución Política del Estado Plurinacional de Bolivia», se encuentra disponible en: http://www.vicepresidencia.gob.bo/Portals/0/documentos/NUEVA_CONSTITUCION_POLITICA_DEL_ESTA DO.pdf. Consultado en agosto de 2009.
}

Fecha de recepción: 12 de agosto de 2010.

Fecha de aceptación: 10 de diciembre de 2010. 